\title{
Thermodynamic and Dynamic Mechanisms for Large-Scale Changes in the Hydrological Cycle in Response to Global Warming*
}

\author{
RICHARD SEAGER AND NAOMI NAIK \\ Lamont-Doherty Earth Observatory, Columbia University, Palisades, New York \\ GABRIEL A. VECCHI \\ Geophysical Fluid Dynamics Laboratory, Princeton, New Jersey
}

(Manuscript received 3 February 2010, in final form 29 April 2010)

\begin{abstract}
The mechanisms of changes in the large-scale hydrological cycle projected by 15 models participating in the Coupled Model Intercomparison Project phase 3 and used for the Intergovernmental Panel on Climate Change's Fourth Assessment Report are analyzed by computing differences between 2046 and 2065 and 1961 and 2000. The contributions to changes in precipitation minus evaporation, $P-E$, caused thermodynamically by changes in specific humidity, dynamically by changes in circulation, and by changes in moisture transports by transient eddies are evaluated. The thermodynamic and dynamic contributions are further separated into advective and divergent components. The nonthermodynamic contributions are then related to changes in the mean and transient circulation. The projected change in $P-E$ involves an intensification of the existing pattern of $P-E$ with wet areas [the intertropical convergence zone (ITCZ) and mid- to high latitudes] getting wetter and arid and semiarid regions of the subtropics getting drier. In addition, the subtropical dry zones expand poleward. The accentuation of the twentieth-century pattern of $P-E$ is in part explained by increases in specific humidity via both advection and divergence terms. Weakening of the tropical divergent circulation partially opposes the thermodynamic contribution by creating a tendency to decreased $P-E$ in the ITCZ and to increased $P-E$ in the descending branches of the Walker and Hadley cells. The changing mean circulation also causes decreased $P-E$ on the poleward flanks of the subtropics because the descending branch of the Hadley Cell expands and the midlatitude meridional circulation cell shifts poleward. Subtropical drying and poleward moistening are also contributed to by an increase in poleward moisture transport by transient eddies. The thermodynamic contribution to changing $P-E$, arising from increased specific humidity, is almost entirely accounted for by atmospheric warming under fixed relative humidity.
\end{abstract}

\section{Introduction}

The models that were run as part of the Coupled Model Intercomparison Project phase 3 (CMIP3; Meehl et al. 2007a), and used for the Intergovernmental Panel on Climate Change's Fourth Assessment Report (IPCC AR4), robustly predict large-scale changes in the hydrological cycle as a consequence of rising greenhouse gases and resulting global warming. To zeroth order these can be described as "wet getting wetter and dry

* Lamont-Doherty Earth Observatory Contribution Number 7374.

Corresponding author address: Richard Seager, Lamont-Doherty Earth Observatory, Columbia University, 61 Rt. 9W, Palisades, NY 10964.

E-mail: seager@1deo.columbia.edu getting drier" or "rich-get-richer." That is, already wet areas of the deep tropics and midlatitudes will get wetter and arid and semiarid regions in the subtropics will get drier (Held and Soden 2006; Meehl et al. 2007b; Chou et al. 2009). Such large-scale changes to the hydrological cycle, if they occur, will have important consequences for human societies and ecosystems. For example, already wet areas could be subject to increased flooding, while already dry areas could see further reductions of available water and water quality as they transition to a drier climate. Even though all of the 24 models that were used within IPCC AR4 exhibit this change in the hydrological cycle, albeit with differences, it is important to know exactly how it occurs and why. Such knowledge will enable a better assessment of the reliability of the climate model projections. 
The main argument to date for why wet regions will get wetter and dry regions get drier is that of Held and Soden (2006). ${ }^{1}$ First of all, the reason that precipitation $P$ minus evaporation $E$, the net flux of water substance at the earth's surface, varies so much spatially is because of the transport of water vapor (and, to a much lesser extent, condensate) in the atmosphere by the mean and time-varying flow. The wettest regions on the planet are in the deep tropics, where the trade winds converge with moisture and $P$ exceeds $E$. Monsoonal regions are other places where $P-E$ is strongly positive. In some midand high-latitude regions, there are also regions of strong $P-E$, with the atmospheric moisture convergence being supplied by a mix of transient eddies (storm systems) and the mean flow in planetary stationary waves. The coasts of northwestern North America and northwestern Europe are examples. In the subtropical regions, a combination of moisture divergence by the trade winds, stationary waves, and transient eddies cause strongly negative $P-E$ over the oceans. As Held and Soden (2006) point out, a warming atmosphere will cause an increase in atmospheric water vapor. Hence, even if the circulation were to remain fixed, it would be expected that the transports of water vapor would intensify. Consequently, under these assumptions, the pattern of $P-E$ will remain the same but the values will become more extreme, making wet regions wetter and dry regions drier.

As Held and Soden (2006) show (their Fig. 7), simply assuming that specific humidity will rise according to the Clausius-Clapeyron relation with fixed relative humidity leads to a prediction of the change in $P-E$ which matches very well with that actually projected by the CMIP3/IPCC AR4 models. This agreement argues for the importance of thermodynamic controls on changing $P-E$. However, as also seen in their Fig. 7, this simple argument predicts increasing $P-E$ over all land areas. This is because, in the absence of unquenchable surface water supply (like the ocean), the climatological mean $P-E$ has to be zero or positive averaged over a catchment basin and balanced by surface and subsurface flow back to the ocean. However, there are many regions where, in contrast to the simple argument, $P-E$ becomes less positive over land (e.g., southwestern North America; Seager et al. 2007). Further, Held and Soden (2006) also show that the simple thermodynamic prediction of changing $P-E$ cannot account for a poleward expansion of the latitude that, in the zonal mean,

\footnotetext{
${ }^{1}$ Emori and Brown (2005) performed a very different means of breaking down precipitation changes into "dynamic" and "thermodynamic" components based on the probability density function of the vertical velocity field.
}

separates the region of negative $P-E$ in the subtropics and positive $P-E$ in midlatitudes. Further, Chou et al. (2009) have shown that within the tropics, dynamical changes (e.g., changes in vertical motion and convergence zone shifts) are required, along with changes in humidity, to entirely explain changes in precipitation.

Consequently, a full accounting of projected changes in $P-E$ requires an extension of the Held and Soden (2006) argument. In particular, the extent to which changes in atmospheric circulation affect $P-E$ as well as the mechanisms for changes in $P-E$ over land and how changes in transient eddy moisture fluxes, either due to changes in eddy intensity or location, affect $P-E$ all need to be evaluated. In this paper we will

1) Conduct a detailed analysis of the changes in the moisture budget in the twenty-first century for the 15 CMIP3/IPCC AR4 models for which all the needed data were archived and made available.

2) Break down the changes in moisture budget into those due to changes in specific humidity (the thermodynamic component), mean circulation (the dynamic component), and transient eddy moisture flux convergence.

3) Relate the dynamic components of the moisture budget change to changes in the circulation.

This extends work already done by Seager and Vecchi (2010) by completing the moisture budget breakdown and taking a global perspective compared to their North American focus. The work provides the most thorough account to date of projected changes in the atmospheric hydrological cycle that are anticipated as a consequence of rising greenhouse gases.

\section{Models and methods}

We examined all 24 models that comprise the CMIP3 database (Meehl et al. 2007a) and that were used as part of the IPCC AR4 to check that all the data required to calculate a moisture budget were available. This requires daily data for specific humidity and winds on standard pressure levels. Only 15 models, listed in Table 1 , had all of the needed data (some models had all the data but contained a lot of bad humidity data that could not be reasonably fixed, so these models were discarded). With these 15 models, we performed moisture budget calculations for two periods for which daily data were saved: 1961-2000 and 2046-65. The 1961-2000 simulations were forced with historical trace gas, aerosol, solar and volcanic forcings, and, in some cases, changes in land use, albeit with differences between models in how these forcings were treated; the 2046-65 simulations used the "middle of the road" emissions 
TABLE 1. Models used in this study, the country of origin, the horizontal resolution of the atmosphere component, and the run used in the analysis. References to these models can be found in Vecchi and Soden (2007). The asterisk denotes that bad humidity data on day 256 of 1986 was replaced by interpolated data from adjacent days.

\begin{tabular}{|c|c|c|c|c|}
\hline & Model & Country & $\begin{array}{l}\text { Atmospheric horizontal } \\
\text { resolution }\end{array}$ & $\begin{array}{l}\text { Run No. } \\
1961-2000 / 2046-65\end{array}$ \\
\hline 1 & $\begin{array}{l}\text { Canadian Centre for Climate Modelling } \\
\text { and Analysis (CCCma) Coupled General } \\
\text { Circulation Model, version 3.1 (CGCM3.1 T47) }\end{array}$ & Canada & $\mathrm{T} 47$ & run1/run1 \\
\hline 2 & CGCM3.1 T63 & Canada & T63 & run1/run1 \\
\hline 3 & $\begin{array}{l}\text { Centre National de Recherches Météorologiques Coupled } \\
\text { Global Climate Model, version } 3 \text { (CNRM-CM3) }\end{array}$ & France & T63 & run1/run1 \\
\hline 4 & $\begin{array}{l}\text { Commonwealth Scientific and Industrial Research } \\
\text { Organisation Mark version } 3.5 \text { (CSIRO Mk3.5) }\end{array}$ & Australia & T63 & run1/run1 \\
\hline 5 & GFDL CM2.0 & United States & $2.5^{\circ} \times 2^{\circ}$ & run1/run1 \\
\hline 6 & GFDL CM2.1 & United States & $2.5^{\circ} \times 2^{\circ}$ & run2/run1 \\
\hline 7 & $\begin{array}{l}\text { Goddard Institute for Space Studies Atmosphere-Ocean } \\
\text { Model (GISS-AOM) }\end{array}$ & United States & $4^{\circ} \times 3^{\circ}(\mathrm{C}$ grid $)$ & run1/run1 \\
\hline 8 & $\begin{array}{l}\text { Goddard Institute for Space Studies Model, version E3 } \\
\text { coupled with Russell ocean model (GISS-ER) }\end{array}$ & United States & $5^{\circ} \times 4^{\circ}(\mathrm{B}$ grid $)$ & run1/run1 \\
\hline 9 & $\begin{array}{l}\text { Institute of Atmospheric Physics Flexible Global } \\
\text { Ocean-Atmosphere-Land System Model (IAP FGOALS) }\end{array}$ & China & $\mathrm{T} 42$ & run1/run2 \\
\hline 10 & $\begin{array}{l}\text { Institute for Numerical Mathematics Climate Model, } \\
\text { version 3.0 (INMCM3.0) }\end{array}$ & Russia & $5^{\circ} \times 4^{\circ}$ & run1/run1 \\
\hline 11 & $\begin{array}{l}\text { L'Institut Pierre-Simon Laplace Coupled Model, } \\
\text { version 4A (IPSL CM4A) }\end{array}$ & France & $2.5^{\circ} \times 3.75^{\circ}$ & run1/run1 \\
\hline 12 & $\begin{array}{l}\text { Meteorological Institute of the University of Bonn, } \\
\text { ECHAM + Global Hamburg Ocean Primitive } \\
\text { Equation (HOPE-G) Model (MIUBECHOG) }\end{array}$ & Germany/Korea & $\mathrm{T} 30$ & run $1 * /$ run 1 \\
\hline 13 & $\begin{array}{l}\text { Model for Interdisciplinary Research on } \\
\text { Climate 3.2, medium-resolution version } \\
\text { [MIROC3.2(medres)] }\end{array}$ & Japan & $\mathrm{T} 42$ & run1/run1 \\
\hline 14 & $\begin{array}{l}\text { Max Planck Institute European Centre Hamburg } \\
\text { Model, fifth generation (MPI ECHAM5) }\end{array}$ & Germany & T63 & run1/run2 \\
\hline 15 & $\begin{array}{l}\text { Meteorological Research Institute Coupled } \\
\text { General Circulation Model, version } 2.3 \\
\text { (MRI CGCM2.3) }\end{array}$ & Japan & $\mathrm{T} 42$ & run1/run1 \\
\hline
\end{tabular}

scenario-Special Report on Emission Scenarios A1B (SRESA1B).

The moisture budget equation to be analyzed is

$$
\begin{aligned}
\rho_{w} g(P-E)= & -\int_{0}^{p_{s}}(\overline{\mathbf{u}} \cdot \nabla \bar{q}+\bar{q} \nabla \cdot \overline{\mathbf{u}}) d p \\
& -\int_{0}^{p_{s}} \nabla \cdot\left(\overline{\mathbf{u}^{\prime} q^{\prime}}\right) d p-q_{s} \mathbf{u}_{s} \cdot \nabla p_{s} .
\end{aligned}
$$

Overbars indicate monthly means and primes indicate departures from the monthly mean, $p$ is pressure, $q$ is specific humidity, $\overline{\mathbf{u}}$ is the horizontal vector wind, $\rho_{w}$ is the density of water, and the subscript $s$ denotes surface values [see Trenberth and Guillemot (1995) for a complete derivation]. The first integral on the right-hand side describes moisture convergence by the mean flow and the second term by the transient eddies. The final term (which has not been broken into monthly-mean and transient components) involves surface quantities. It was evaluated for the Geophysical Fluid Dynamics
Laboratory Climate Model version 2.1 (GFDL CM2.1) using daily data and was found to have peak values a few times smaller than peak values of the other terms. Few models have archived daily values of all these surface quantities. However, we found in the GFDL CM2.1 model that this term was reasonably approximated when evaluated using monthly-mean values alone. Therefore, we evaluated it with monthly means for all 15 models and using the lowest pressure level values if surface quantities were not evaluated. We discuss this surface term $S$, which provides a positive $P-E$ tendency because of surface flow down the pressure gradient, no further, but its zonal mean change is shown (see Fig. 12).

Denoting

$$
\delta(\cdot)=(\cdot)_{21}-(\cdot)_{20},
$$

where subscripts 20 and 21 indicate twentieth-century and twenty-first-century values of the arbitrary quantity in parentheses, respectively, Eq. (1) can be approximated as 


$$
\begin{aligned}
\rho_{w} g \delta(P-E) \approx & -\int_{0}^{p_{s}}\left(\delta \overline{\mathbf{u}} \cdot \nabla \bar{q}_{20}+\overline{\mathbf{u}}_{20} \cdot \nabla \delta \bar{q}+\delta \bar{q} \nabla \cdot \overline{\mathbf{u}}_{20}\right. \\
& \left.+\bar{q}_{20} \nabla \cdot \delta \overline{\mathbf{u}}\right) d p-\int_{0}^{p_{s}} \nabla \cdot \delta\left(\overline{\mathbf{u}^{\prime} q^{\prime}}\right) d p-\delta S .
\end{aligned}
$$

In Eq. (3) terms involving changes in $q$ but no changes in $\mathbf{u}$ are referred to as themodynamic contributors to changes in $P-E$ and terms involving changes in $\mathbf{u}$ but no changes in $q$ as dynamic contributors. Note that since the transient eddy moisture convergence is a covariance, there is no straightforward way to divide it into contributions from changes in eddy humidity and eddy flow; therefore, we leave it as is [see Wu et al. (2010) for an effort to break down the eddy fluxes into components using mixing length theory]. In progressing from Eq. (1) to Eq. (3), we have neglected the nonlinear term that is the product of changes in both time mean specific humidity and flow [i.e., $\left.\delta \mathrm{NL}=-\int_{0}^{p_{s}} \nabla \cdot(\delta \bar{q} \delta \overline{\mathbf{u}}) d p\right]$. The time mean specific humidity and flow terms were evaluated and found to be small and hence the implicit linearization in progressing from Eq. (1) to Eq. (3) is reasonable.

In the following equations, it will be useful to consider the breakdown in Eq. (3); however, it is also useful to combine the breakdown into thermodynamic $\mathrm{TH}$, mean circulation dynamics $\mathrm{MCD}$, and transient eddy TE contributors to changes in $P-E$ as

$$
\begin{aligned}
\rho_{w} g \delta(P-E) \approx \delta \mathrm{TH}+\delta \mathrm{MCD}+\delta \mathrm{TE}-\delta S, \\
\delta \mathrm{TH}=-\int_{0}^{p_{s}} \nabla \cdot\left(\overline{\mathbf{u}}_{20}[\delta \bar{q}]\right) d p, \\
\delta \mathrm{MCD}=-\int_{0}^{p_{s}} \nabla \cdot\left([\delta \overline{\mathbf{u}}] \bar{q}_{20}\right) d p, \quad \text { and } \\
\delta \mathrm{TE}=-\int_{0}^{p_{s}} \nabla \cdot \delta\left(\overline{\mathbf{u}^{\prime} q^{\prime}}\right) d p .
\end{aligned}
$$

To compute as accurate a moisture balance as possible, we use the finest temporal resolution data available for the 3D atmospheric fields, and we use the horizontal and vertical grids for each model as archived in the CMIP3 archive. Our balance equations are approximate, since we do not have data available on the model native grid nor on the model computational time step. Thus, to evaluate these terms, we make no attempt to use the numerical methods used within the individual models; instead, the moisture budgets are calculated for each of the 15 models individually by vertically integrating the terms in the moisture conservation equation on the nine standard pressure levels that the data were archived on and using discretized spherical divergence and gradient operators on the original model horizontal grids.
The spatial derivatives are discretized with centered second-order differences dropping to one-sided firstorder differences at points adjacent to undefined values. For each model, the wind and humidity are assumed to be undefined on a given pressure level whenever the pressure level exceeds the surface pressure. Although most of the model data are available on an "A grid," with all data on the same longitude/latitude grid, a few of the models provide their data on " $\mathrm{B}$ " or " $\mathrm{C}$ " grids, for which some values are given on staggered grid points. In these cases, we first interpolate all data to the humidity grid.

The vertical integral is performed on the standard pressure level grid assuming a piecewise linear profile from the surface pressure to the top level and integrating exactly to give a second-order approximation. The multimodel mean is then calculated by interpolating to a common $2.5 \times 2.5$ latitude-longitude-degree global grid and then averaging over all 15 models. There remains a nonnegligible residual between the change in $P-E$ and the calculated change in moisture convergence that is shown and discussed in the appendix.

\section{The climatological twentieth-century hydrological cycle in the CMIP3/IPCC AR4 models}

To provide context for the analysis of projected changes in the hydrological cycle, we first present the climatological hydrological cycle averaged over 1961-2000 as simulated in the CMIP3/IPCC AR4 models. Figures 1 and 2 show $P-E,-\int_{0}^{p_{s}} \overline{\mathbf{u}} \cdot \nabla \bar{q} d p,-\int_{0}^{p_{s}} \bar{q} \nabla \cdot \overline{\mathbf{u}} d p$, and $-\int_{0}^{p_{s}} \boldsymbol{\nabla} \cdot\left(\overline{\overline{\mathbf{u}}^{\prime} q^{\prime}}\right) d p$ during the October-March and AprilSeptember half years, respectively. The $P-E$ plots show the characteristic banded structure during both half years, with positive values in the intertropical convergence zone (ITCZ) and monsoons, and weaker positive values at mid- to high latitudes and negative values in the subtropics. The negative regions are more zonal during the winter half year and clearly related to the subsiding branch of the Hadley cell, while during the summer half year, negative $P-E$ is concentrated over the eastern subtropical oceans under the subsiding flanks of the subtropical anticyclones. The link to the divergent circulation is confirmed by the close match in the tropics and subtropics between $P-E$ and the $-\int_{0}^{p_{s}} \bar{q} \boldsymbol{\nabla} \cdot \overline{\mathbf{u}} d p$ term. The advection term $-\int_{0}^{p_{s}} \overline{\mathbf{u}} \cdot \nabla \bar{q} d p$ dries in regions of equatorward advection in the trade winds and provides a tendency to positive $P-E$ over the mid- and high-latitude oceans where the flow is poleward. Transient eddies dry the subtropics and moisten the mid- to high latitudes, especially over the oceans where the storm tracks are at their strongest (Chang et al. 2002). 

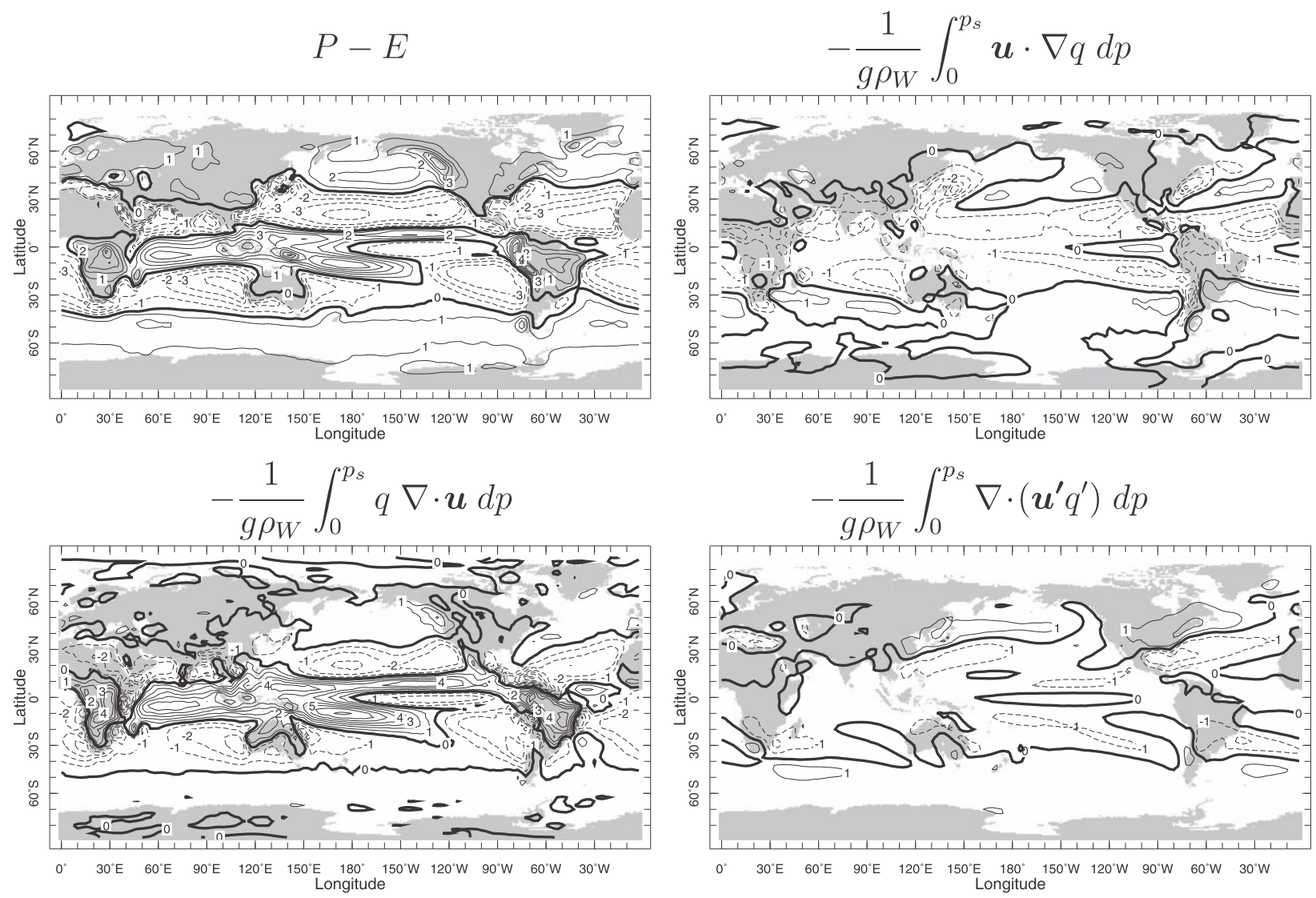

FIG. 1. The climatological, multimodel ensemble mean moisture budget for October-March 1961-2000. Shown are (top left) $P-E$, (top right) the advection of humidity by the mean flow, (bottom left) the mean flow convergence of moisture term, and (bottom right) the transient eddy moisture flux convergence. Convergence (divergence) is denoted by positive (negative) contours. Units are millimeters per day.

During winter $P-E$ is positive over most continents. For example, over North America transient eddies converge moisture into the United States, while the mean flow diverges moisture. In the Pacific Northwest of North America, where the mean westerlies impinge on the coastal ranges, there is mean flow moisture convergence. Over the United States, there is a switch to negative $P-E$ during the summer half year sustained by mean flow divergence. The seasonal cycle of $P-E$ is the opposite over monsoonal continents in the subtropics, with mean flow moisture convergence and positive $P-E$ during the summer half years and mean flow moisture divergence and negative $P-E$ during the winter half years.

\section{Contributions to hydrological cycle changes in the twenty-first century}

a. Relative contributions of thermodynamic, mean circulation, and transient eddy processes to changes in the hydrological cycle

Next we address how $P-E$ is projected to change by the middle of the current century and what the mechanisms for this are. Figures 3 and 4 show, during the October-March and April-September half years, respectively, the change in $P-E$, the thermodynamics contribution $\delta \mathrm{TH}$, the contribution from changes in the mean circulation dynamics $\delta \mathrm{MCD}$, and the contribution from changes in transient eddy flux convergence $\delta$ TE. During October-March the entire subtropics in both hemispheres experience reduced $P-E$, there is a narrow band of increased $P-E$ in the deep tropics, and increased $P-E$ in the mid- to high latitudes of both hemispheres. The upper-right panels of Figs. 3 and 4 show that a large portion of the tropical and subtropical change in $P-E$ can be accounted for by $\delta \mathrm{TH}$, including moistening in much of the ITCZ and drying in the trade wind regions. This term follows simply from an increase in specific humidity in a warmer atmosphere and has the spatial pattern of the mean twentieth-century low-level divergence (drying) and convergence (moistening).

However, it is also clear that $\delta \mathrm{TH}$ does not provide a full accounting of the change in $P-E$. $\delta \mathrm{MCD}$ accounts for increased $P-E$ over the equatorial Pacific Ocean. This follows from enhanced SST warming in this 

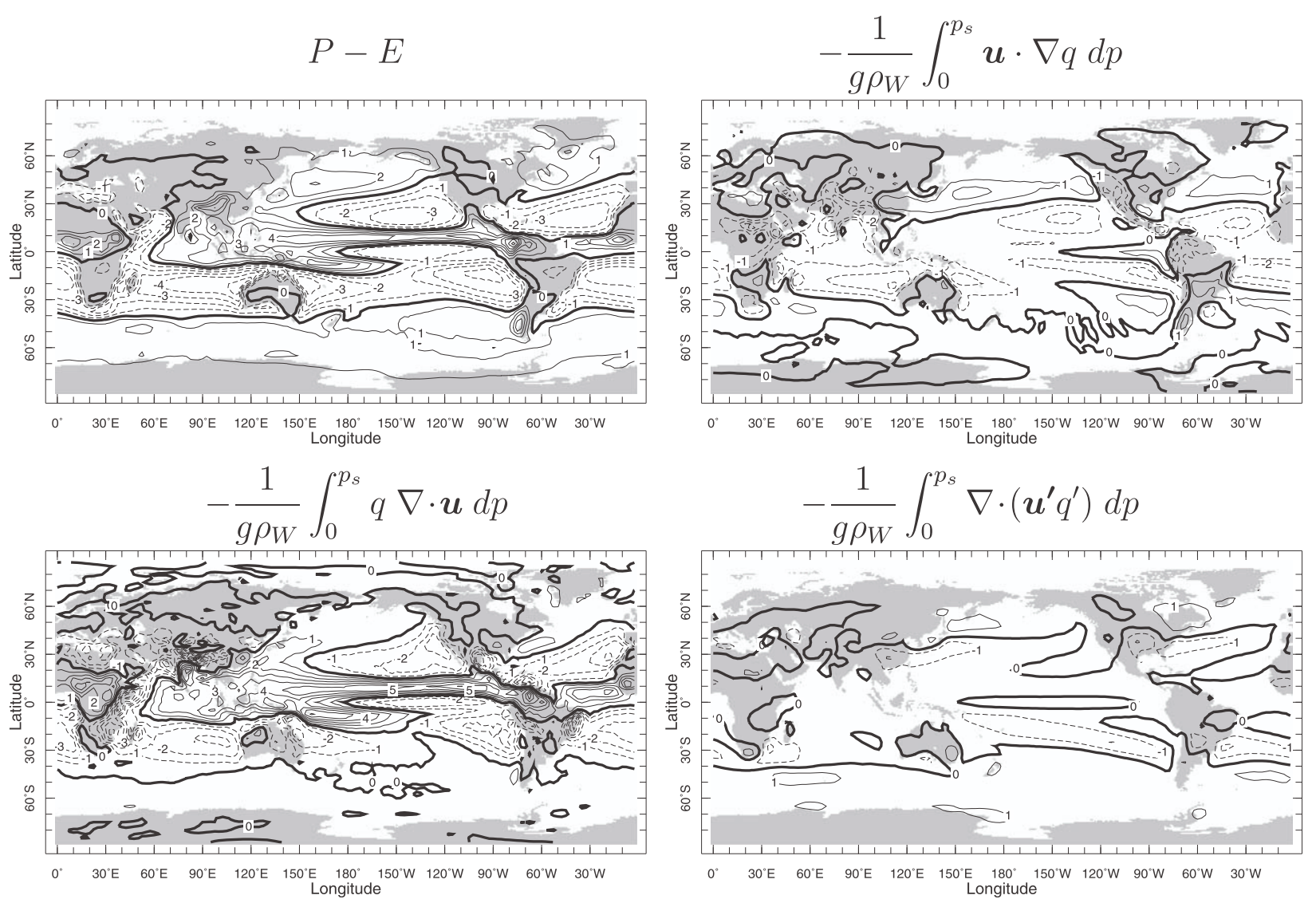

FIG. 2. As in Fig. 1, but for April-September.

area in the model ensemble mean and a reduced eastwest SST gradient (Liu et al. 2005) even as this is not a universal response of the models and, in fact, as many models have an increase in the gradient as a decrease (Seager and Vecchi 2010). It also appears that a tendency to enhanced equatorial Pacific $P-E$ is associated with an ITCZ shift and a tendency to reduced $P-E$ via the $\delta \mathrm{MCD}$ term in the flanking regions. Further poleward there is a tendency to increased $P-E$ via the $\delta \mathrm{MCD}$ term in the trade wind regions that follows from reduced divergence associated with the general weakening of the tropical divergent circulation under global warming (Vecchi and Soden 2007). Further poleward again, the $\delta \mathrm{MCD}$ term contributes drying centered at about $40^{\circ}$ latitude caused by an expansion of the regions of divergence in the subtropics related, in turn, to the expansion of the Hadley cell (Lu et al. 2007; Previdi and Liepert 2007) and the poleward shift of the midlatitude storm tracks (Yin 2005; Bengtsson et al. 2006). This mean circulation dynamics term is responsible in large part for the poleward expansion of the subtropical dry zones.

$\delta$ TE provides a relatively simple pattern in the Northern Hemisphere during both half years of drying at the poleward flank of the subtropics and moistening in higher latitudes. This is caused by a strengthening of the transient eddy moisture transport (Wu et al. 2010). However, in both hemispheres there is also an indication of a poleward shift of the pattern of transient eddy moisture flux in addition to a strengthening. Quite clearly the increased $P-E$ in midlatitude and subpolar regions is driven by increased transient eddy moisture flux convergence.

\section{b. Relative contributions of changes in advection and divergence to the dynamic and thermodynamic components of hydrological cycle change}

It is possible to gain more understanding of the mechanisms of projected hydrological cycle change by further decomposing the thermodynamic and mean circulation dynamics contributions into terms due to the advection of moisture (subscript $A$ ) and the convergence or divergence of moisture (subscript $D$ ). The thermodynamic contribution can be written as

$$
\delta \mathrm{TH}=\delta \mathrm{TH}_{A}+\delta \mathrm{TH}_{D},
$$


$\delta(P-E)$

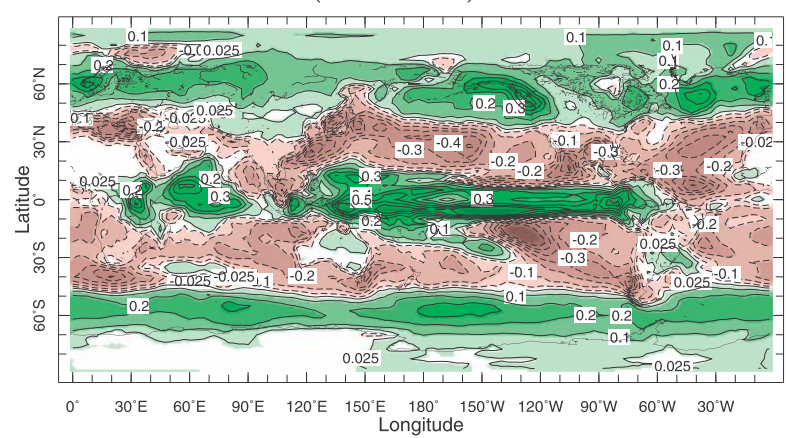

$\delta M C D$

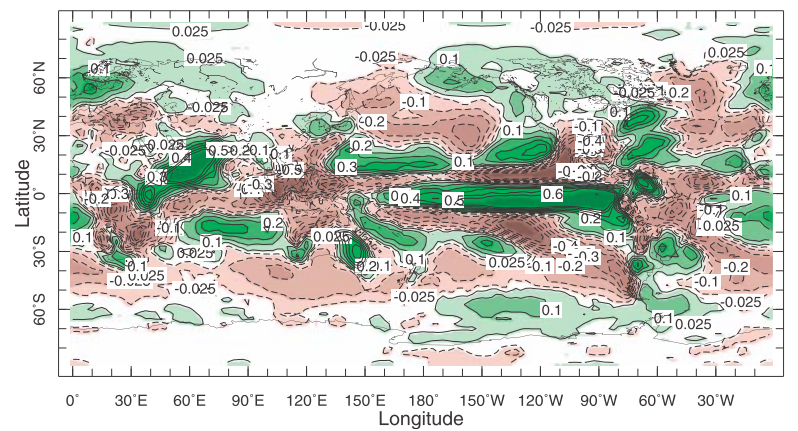

$\delta T H$

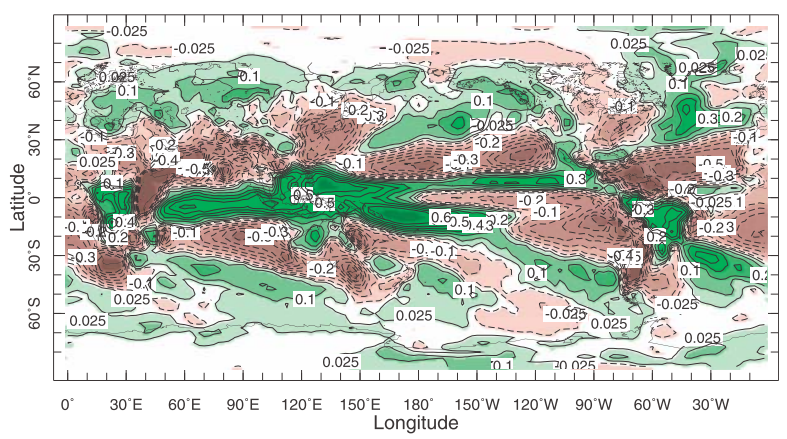

$\delta T E$

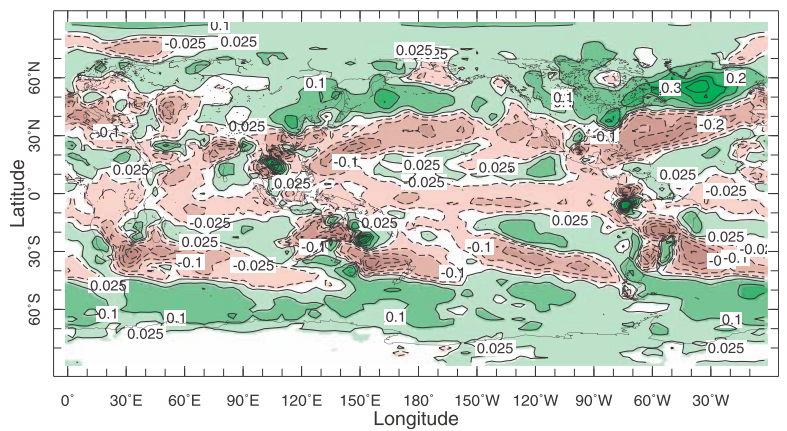

FIG. 3. The multimodel ensemble mean change in the moisture budget for October-March 2046-65 minus 1961-2000. Shown are the (top left) $\delta(P-E)$, (top right) $\delta \mathrm{TH}$, (bottom left) $\delta \mathrm{MCD}$, and (bottom right) $\delta \mathrm{TE}$. Units are millimeters per day.

$$
\begin{aligned}
& \delta \mathrm{TH}_{A}=-\int_{0}^{p_{s}}\left(\overline{\mathbf{u}}_{20} \cdot \nabla \delta \bar{q}\right) d p, \quad \text { and } \\
& \delta \mathrm{TH}_{D}=-\int_{0}^{p_{s}}\left(\delta \bar{q} \boldsymbol{\nabla} \cdot \overline{\mathbf{u}}_{20}\right) d p ;
\end{aligned}
$$

the dynamic contribution can be written as

$$
\begin{aligned}
\delta \mathrm{MCD} & =\delta \mathrm{MCD}_{A}+\delta \mathrm{MCD}_{D}, \\
\delta \mathrm{MCD}_{A} & =-\int_{0}^{p_{s}}\left(\delta \overline{\mathbf{u}} \cdot \nabla \bar{q}_{20}\right) d p, \quad \text { and } \\
\delta \mathrm{MCD}_{D} & =-\int_{0}^{p_{s}}\left(\bar{q}_{20} \nabla \cdot \delta \overline{\mathbf{u}}\right) d p .
\end{aligned}
$$

Figures 5 and 6 show these four terms for the OctoberMarch and April-September half years, respectively. The two terms contributing to the thermodynamic-induced change in $P-E$ are the easiest to understand. Because of the nonlinearity of the Clausius-Clapeyron equation, even for a uniform SST and surface air temperature change, in the absence of any sizable change in relative humidity, the specific humidity increases more over already warm waters than over cooler waters. Hence, the spatial gradients of specific humidity increase under global warming. Consequently, the existing patterns of moisture advection intensify, increasing drying in the equatorwardflowing trade winds and increasing moistening in the poleward-flowing midlatitude westerlies. $\delta \mathrm{TH}_{D}$, is even simpler, contributing a tendency to increased $P-E$ in regions of low-level convergence (the ITCZ and some summer monsoonal regions) and a tendency to reduced $P-E$ in the trade wind regions. It has a weak tendency to moistening in the winter midlatitudes and over the eastern midlatitude oceans during summer [associated with the poleward-flowing and ascending flanks of the subtropical anticyclones (Seager et al. 2003)]; however, this is weaker than in the tropics because, first, the convergence itself is weaker and, second, the change in specific humidity is weaker.

The contribution to the mean circulation-dynamicsinduced change in $P-E$ that arises from $\delta \mathrm{MCD}_{D}$ [i.e., $\left.-\int_{0}^{p_{s}}\left(\bar{q}_{20} \nabla \cdot \delta \overline{\mathbf{u}}\right) d p,\right]$ shows the effect of the weakening tropical divergent circulation strength. In the ITCZ, the weakening of the ascent creates a tendency to reduced $P-E$, while the opposite occurs in the descending branch of the Hadley cell. Along the equatorial Pacific Ocean, there is a tendency to increased $P-E$ that arises 


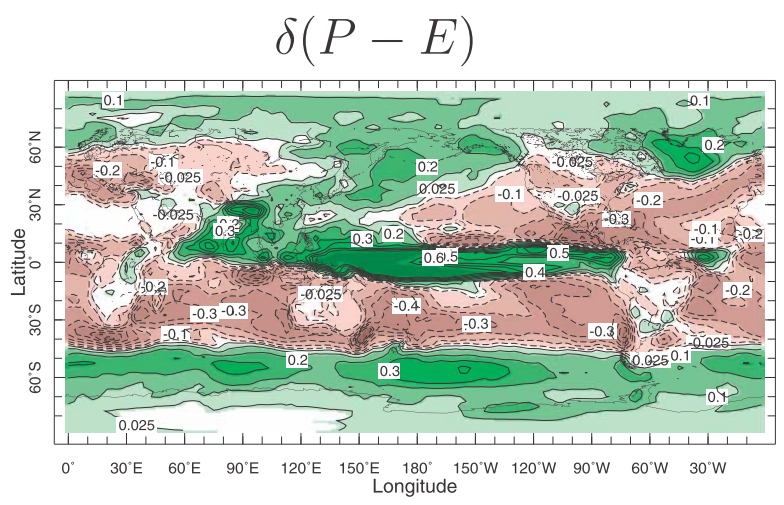

$\delta M C D$

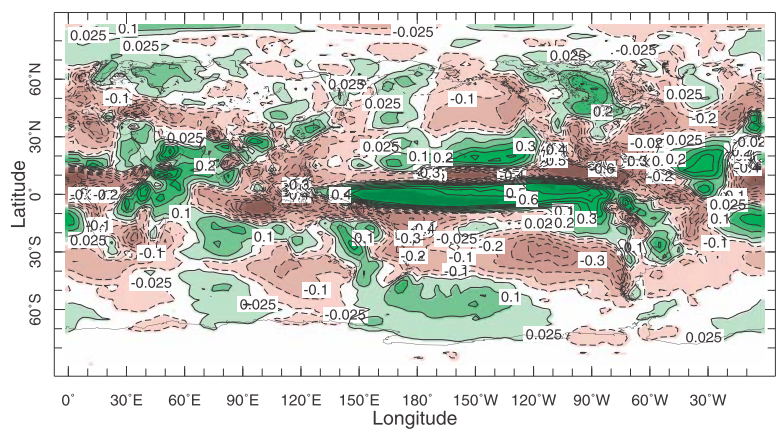

$\delta T H$

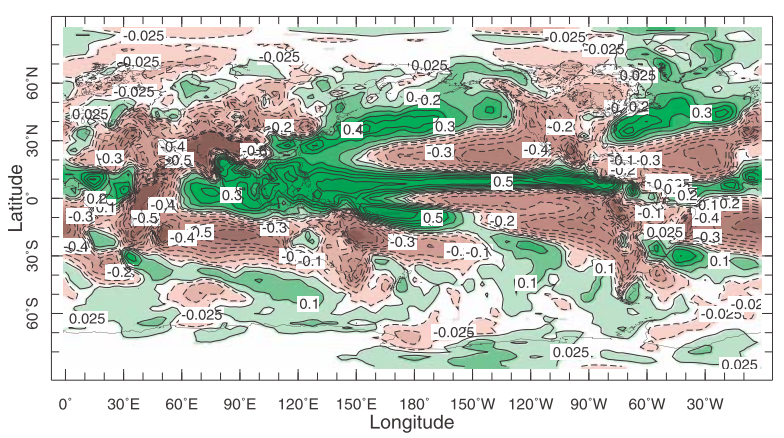

$\delta T E$

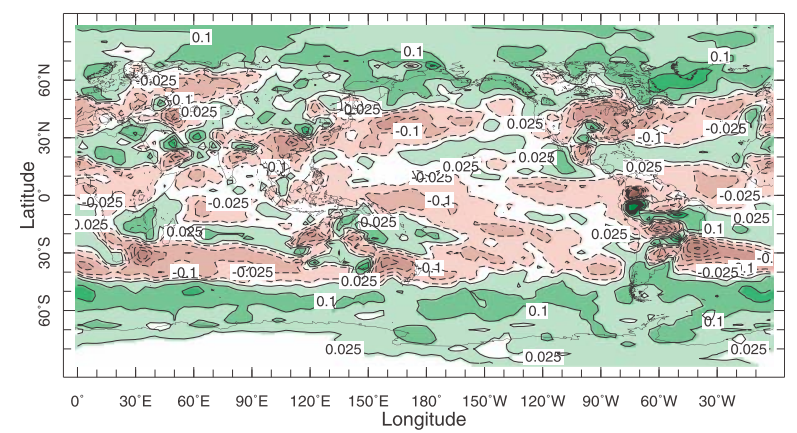

FIG. 4. As in Fig. 3, but for the April-September half years.

from a weaker descending branch of the Walker circulation and an increase in underlying SSTs. On the poleward flanks of the Hadley cell in the subtropics, there is also a tendency toward reduced $P-E$ that comes about from a poleward expansion of the Hadley cell and associated poleward shift of the midlatitude storm tracks and eddy-driven descent on its equatorward side. $\delta \mathrm{MCD}_{A}$ reflects changes in low-level winds (see section 5). In the tropics there is increased drying and a tendency to negative $P-E$, where the trade winds strengthen, as over the southeastern Pacific and North Atlantic; however, in places where the trades weaken, such as over parts of the South Atlantic and North Pacific, there is a tendency to increased $P-E$. Strengthening of the northern winter subpolar lows leads to moistening on their eastern flanks and drying on their western flanks. In the Southern Hemisphere, the poleward expansion of the region of drying within the trade winds is also seen with a tendency to negative $P-E$ at about $30^{\circ}-40^{\circ}$ south.

\section{Relating the mean circulation dynamics contributions to changes in $P-E$ to changes in the general circulation}

It has been shown that changes in the mean circulation and transient eddy fluxes contribute significantly to projected changes in $P-E$ in addition to the changes induced thermodynamically by rising specific humidity. Next we relate the dynamic contributions to changes in $P-E$ to changes in the mean circulation itself.

Figure 7 shows the $925-\mathrm{mb}$ climatological divergence field together with the change from the twentieth to the twenty-first century. The weakening of the tropical divergent circulation is clearly seen with anomalous divergence in regions of mean convergence (the ITCZ) and vice versa (the trade winds). As shown by Vecchi and Soden (2007), this weakening is also seen in midtropospheric vertical velocity, with changes acting to oppose the mean vertical velocity. Weakening of the tropical divergent circulation would reduce contrasts in $P-E$ within the tropics as shown in Figs. 3-6, although this tendency is overwhelmed by the opposite tendency caused by rising specific humidity. It is also clear that in the twenty-first century, there is increased divergence on the poleward flanks of the twentieth-century divergence field, for example, across the Southern Ocean and over the North Pacific and, to a lesser extent, over the North Atlantic. Further poleward there is an increase in convergence. The shifts in the convergence and divergence patterns of the circulation are related to both a prior documented poleward expansion of the Hadley cell ( $\mathrm{Lu}$ et al. 2007), which expands the region of trade wind 

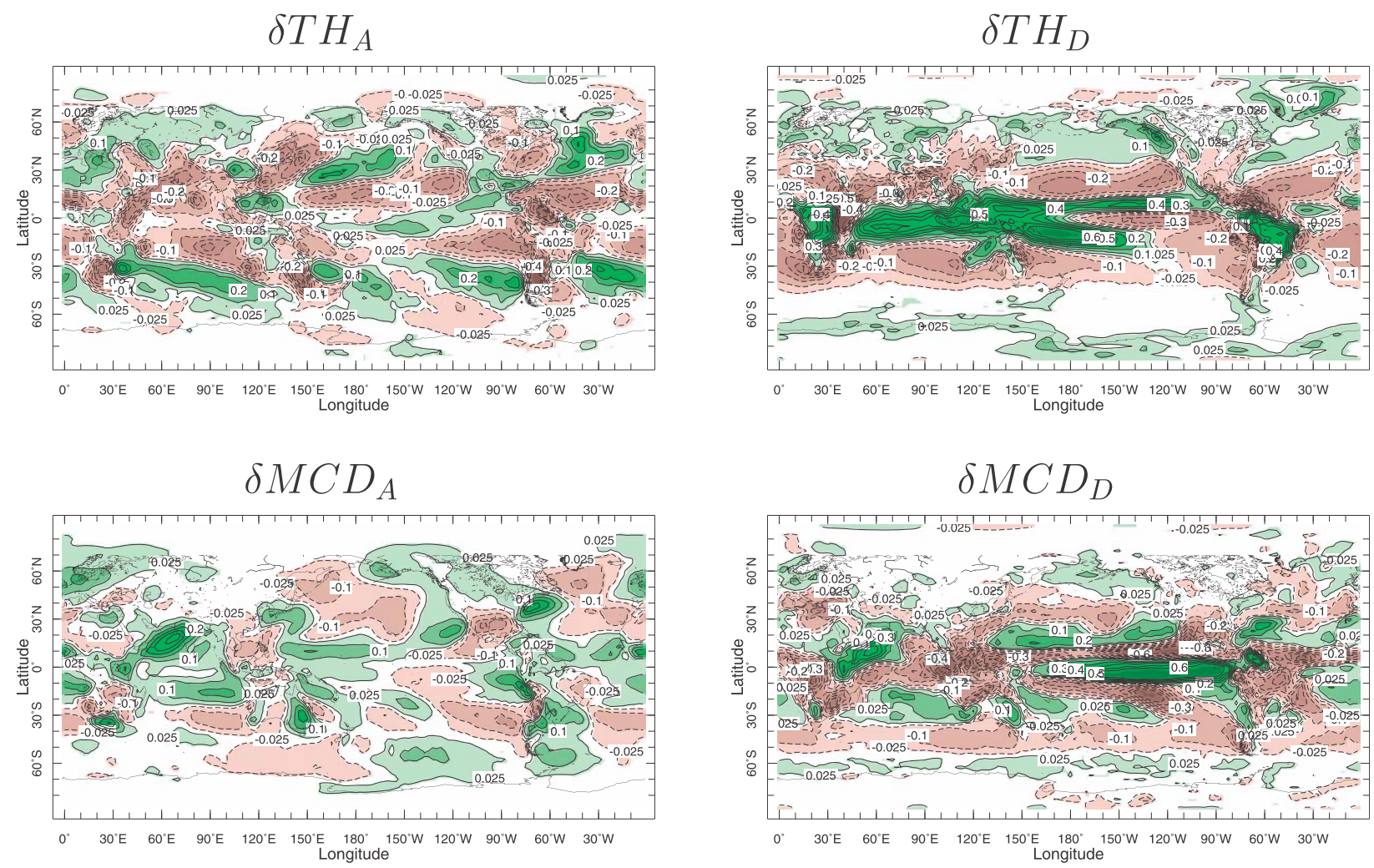

FIG. 5. Decomposition of the change in the multimodel ensemble mean thermodynamic and dynamic contributions to the change in the moisture budget for October-March 2046-65 minus 1961-2000. Shown are (top left) $\delta \mathrm{TH}_{A}$, (top right) $\delta \mathrm{TH}_{D}$, (bottom left) $\delta \mathrm{MCD}_{A}$, and (bottom right) $\delta \mathrm{MCD}_{D}$. Units are millimeters per day.

divergence, and a poleward shift of the storm tracks (Yin 2005). The convergence of momentum fluxes within the transient eddies induces descent, and low-level divergence, on the equatorward flank of the storm track and ascent, and low-level convergence, on the poleward flank (e.g., Holton (1992), chapter 10). As the storm tracks and their patterns of momentum flux convergence shift poleward in the twenty-first century, the induced dipole of divergence and convergence will also shift poleward.

Figure 8 shows the change in winds at $925 \mathrm{mb}$ together with the change in moisture advection due to this change in circulation for both half years. There is a clear match between areas of change toward more poleward flow and a tendency to increased $P-E$ and areas of change toward more equatorward flow and a tendency to decreased $P-E$. The poleward shift of the Southern Hemisphere westerlies is seen but, in general, the change in flow is quite complex and lacks any simple explanation. For example, in the subtropics the southeastern Pacific trades strengthen during both half years but the southeastern Atlantic trades weaken. The North Pacific and Atlantic summer subtropical anticyclones strengthen on their northern sides. During the northern winter half year, there is some evidence of the poleward shift of the westerlies.

The weakening of the tropical divergent circulation, and the strengthening in some regions of the trade winds, are not inconsistent with each other. The trade winds contain divergent and rotational components. Figure 9 shows the surface pressure change from the twentieth to the twenty-first century together with the twentiethcentury $925-\mathrm{mb}$ climatological specific humidity field. There are maxima of surface pressure increase in the subtropics and subtropical-to-midlatitude regions of both hemispheres that reflect an intensification and poleward spreading of the subtropical highs. The tendency to stronger trades arises from the geostrophic balance with this global-warming-induced increase in the surface pressure of the subtropical high pressure zones. As can be seen from Fig. 9, the changed geostrophic winds in balance with the changed surface pressure field will strengthen advective drying, and create a negative $P-E$ tendency, over the subtropical southeastern Pacific Ocean and subtropical North Atlantic Ocean (Figs. 5 and 6). The dynamical reason for the increases in intensity of the subtropical highs is as yet unknown; however, there is no doubt related to the Hadley cell 


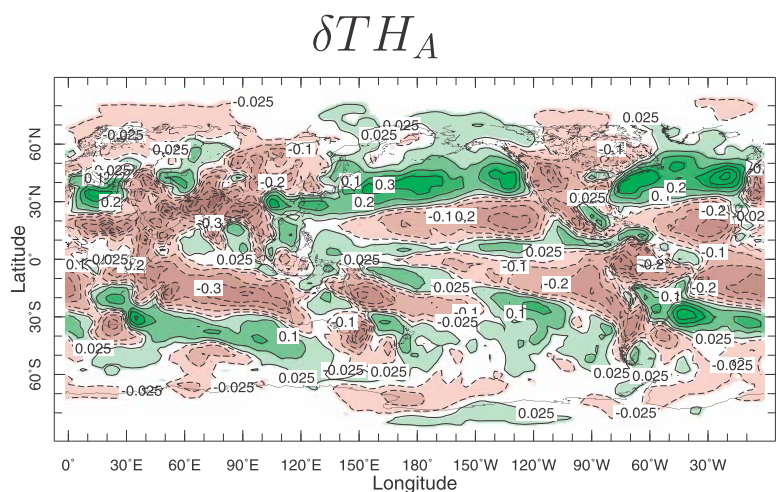

$\delta M C D_{A}$

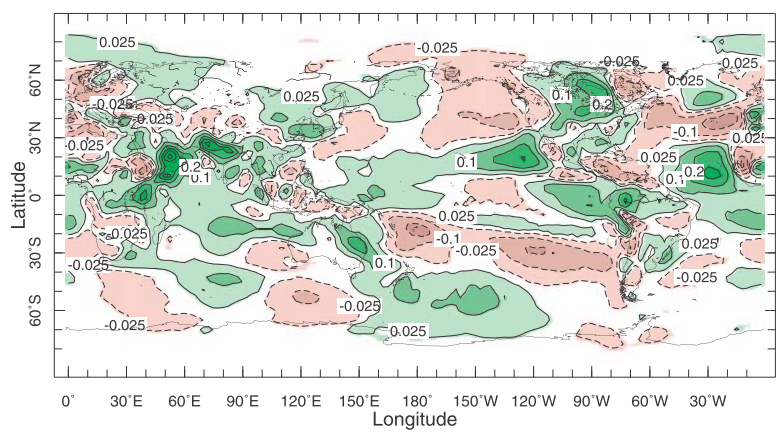

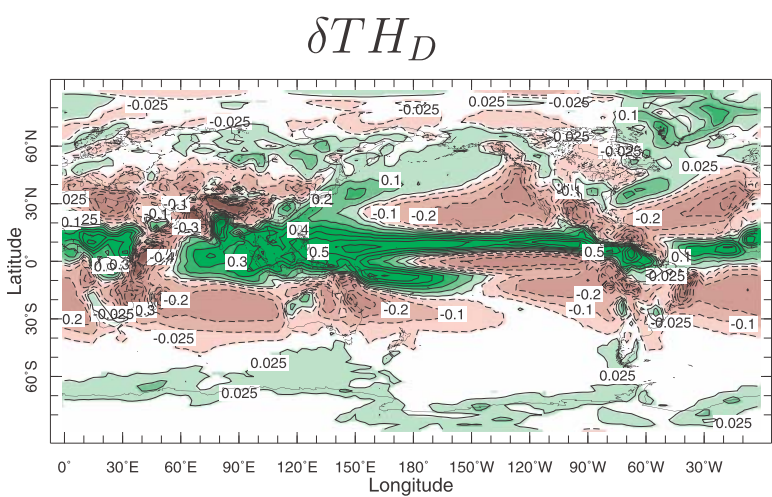

$\delta M C D_{D}$

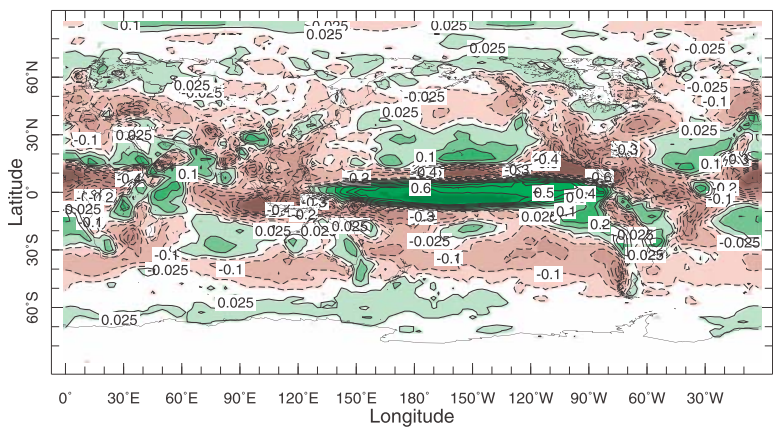

FIG. 6. As in Fig. 5, but for the April-September half year.

expansion and poleward shifts of the midlatitude westerlies and storm tracks. Xie et al. (2010) have suggested as much for the southeastern Pacific case. They also note that the southeastern Pacific is a region of weak projected global warming because a radiatively driven strengthening of the trade winds (by an unknown mechanism) cools the SST and is then amplified by a positive wind-evaporation-SST feedback that strengthens both the cooling and trade winds.

\section{Contributions of fixed and varying relative humidity to the thermodynamic contribution to changing $\boldsymbol{P}-\boldsymbol{E}$}

What we have called the thermodynamic contribution to changing $P-E$ involves changes in specific humidity only, with the circulation held fixed. However, the change in specific humidity could itself be influenced by changes in circulation. One way to break down the determining factors further is to calculate the changes in $P-E$ that would occur if both the relative humidity and the circulation remained unchanged. In this case the specific humidity only changes because the temperature of the atmosphere changes and not because patterns of moisture transport change. Of course, the temperature change itself includes an influence of changes in circulation, and we can never really isolate a purely thermodynamic contribution; however, this additional breakdown still includes a useful further check on mechanisms.

The change in specific humidity can be written as

$$
\delta \bar{q}=\delta\left(r \bar{q}_{s}\right)=\left(r_{20}+\delta r\right) \bar{q}_{S_{21}}-r_{20} \bar{q}_{s_{20}}=r_{20} \delta \bar{q}_{s}+\delta r \bar{q}_{s_{21}}
$$

where $r$ is relative humidity and $\bar{q}_{s}$ is saturation specific humidity.

Substituting into Eq. (5), we have

$$
\begin{aligned}
\delta \mathrm{TH} & =\delta \mathrm{TH}_{r_{20}}+\delta \mathrm{TH}_{\delta_{r}}, \\
\delta \mathrm{TH}_{r_{20}} & =-\int_{0}^{p_{s}} \nabla \cdot\left(\overline{\mathbf{u}}_{20}\left[r_{20} \delta \bar{q}_{s}\right]\right) d p, \quad \text { and } \\
\delta \mathrm{TH}_{\delta_{r}} & =-\int_{0}^{p_{s}} \nabla \cdot\left(\overline{\mathbf{u}}_{20}\left[\delta r \bar{q}_{S_{21}}\right]\right) d p,
\end{aligned}
$$

which divides the thermodynamic contribution to changes in $P-E$ into parts due to a change in temperature alone with fixed relative humidity $\delta \mathrm{TH}_{r_{2}}$ and changes in relative humidity $\delta \mathrm{TH}_{\delta}$. Figures 10 and 11 show the total thermodynamic component and its breakdown into these two components for the two half years. Clearly, almost the 

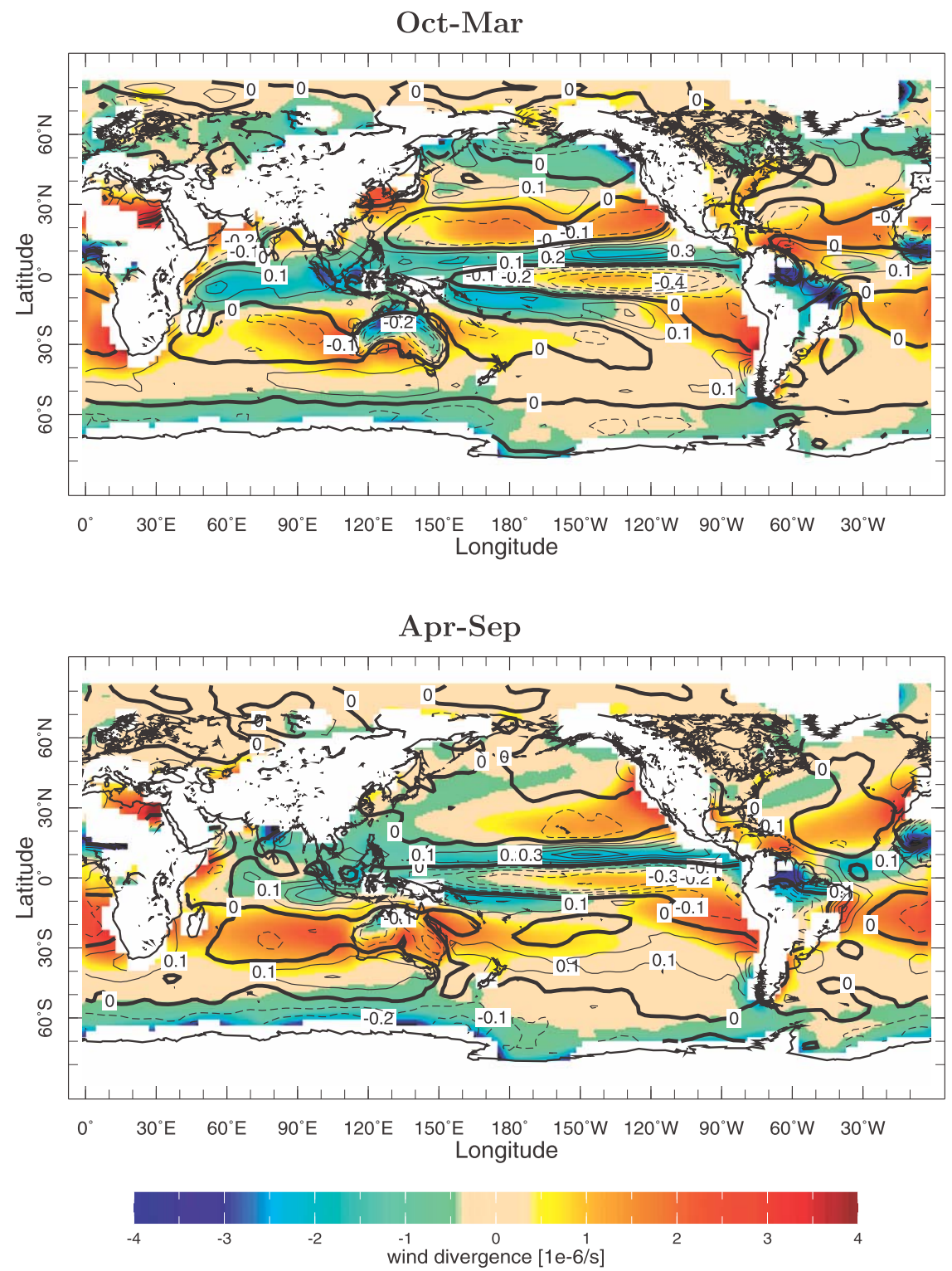

FIG. 7. The twentieth-century divergence at $925 \mathrm{mb}$ (colors, $10^{6} \mathrm{~s}^{-1}$ ) and the twenty-first-century change (contours) for the (top) October-March and (bottom) April-September half years.

entire thermodynamic contribution to changes in $P$ $E$ is indeed accounted for in a simple thermodynamic sense by an increase in specific humidity that follows from atmospheric warming under conditions of fixed relative humidity. This is so regardless of location and season.

\section{Changes in the zonal mean hydrological cycle}

Figure 12 shows the annual and zonal mean change in $P-E$ and the contributions from $\delta \mathrm{TH}, \delta \mathrm{MCD}$, and $\delta \mathrm{TE}$, together with $\delta \mathrm{NL}, \delta S$, and the residual imbalance. The residual, and the two neglected terms, though not negligible, do not interfere with the large-scale patterns of the other terms that combine to explain the changes in $P-E$. The increase of $P-E$ in the deep tropics and higher latitudes, separated by drying in the subtropics, is clearly seen. The thermodynamic term has a similar longitudinal structure; however, even in the deep tropics and subtropics, changes in the mean circulation dynamics contribute strongly to changes in $P-E$. For example, an equatorward shift of the ITCZ region of dynamic moistening is evident. Dynamic drying is also clear on the poleward flank of the subtropical regions of thermodynamic drying, consistent with changes in the mean meridional circulation. Increased transient eddy 

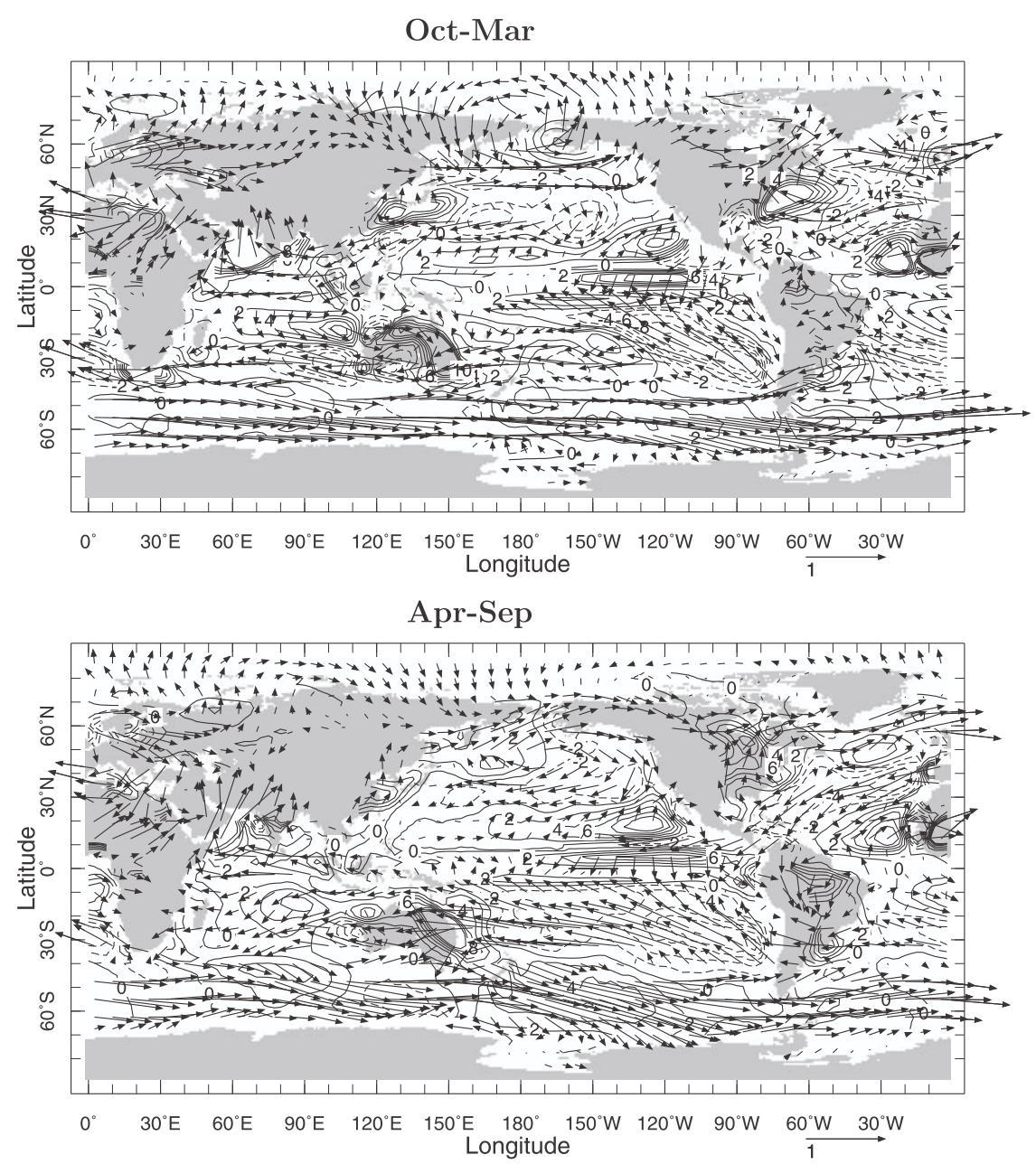

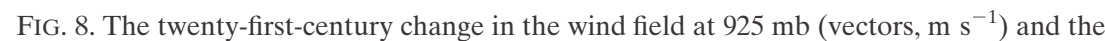
change in moisture advection due to this change in flow (contours, $\mathrm{mm} \mathrm{day}^{-1}$ ) for the (top) October-March and (bottom) April-September half years.

poleward moisture transport contributes strongly to subtropical drying and higher-latitude moistening. In general, the mechanisms of $P-E$ change are quite spatially variable and complex. Nonetheless, Held and Soden (2006) showed that the change in $P-E$ by latitude was proportional to the $P-E$ itself multiplied by the local temperature change. Such a relation apparently arises through a sequence of steps involving thermodynamic changes and changes in the mean circulation and transient eddy moisture transports.

\section{How well can the changes in the hydrological cycle be explained by the Clausius-Clapeyron relation?}

It has recently been argued that the thermodynamic component of the changes in atmospheric water vapor transports can be explained in terms of the moisture-holding capacity of the atmosphere as given by the Clausius-Clapeyron equation with fixed relative humidity (Held and Soden 2006; Lorenz and DeWeaver 2007a). This was confirmed in section 6 , where we showed that the thermodynamic component of $P-E$ change was dominated by the fixed relative humidity contribution. It is also of interest to see to what extent the increase in the transient eddy moisture fluxes can also be explained by the Clausius-Clapeyron relation. Held and Soden (2006) suggested that there should be a correspondence if it is thought that the transient eddy moisture fluxes act diffusively and the mean state moisture gradients increase under global warming according to the Clausius-Clapeyron relation.

To do this we compute Clausius-Clapeyron approximations $\left(\delta \mathrm{TH}_{\mathrm{CC}}\right.$ and $\left.\delta \mathrm{TE}_{\mathrm{CC}}\right)$ to the thermodynamicand transient-eddy-induced changes in $P-E$ ( $\delta \mathrm{TH}$ and $\delta \mathrm{TE})$ as follows: 
Oct-Mar
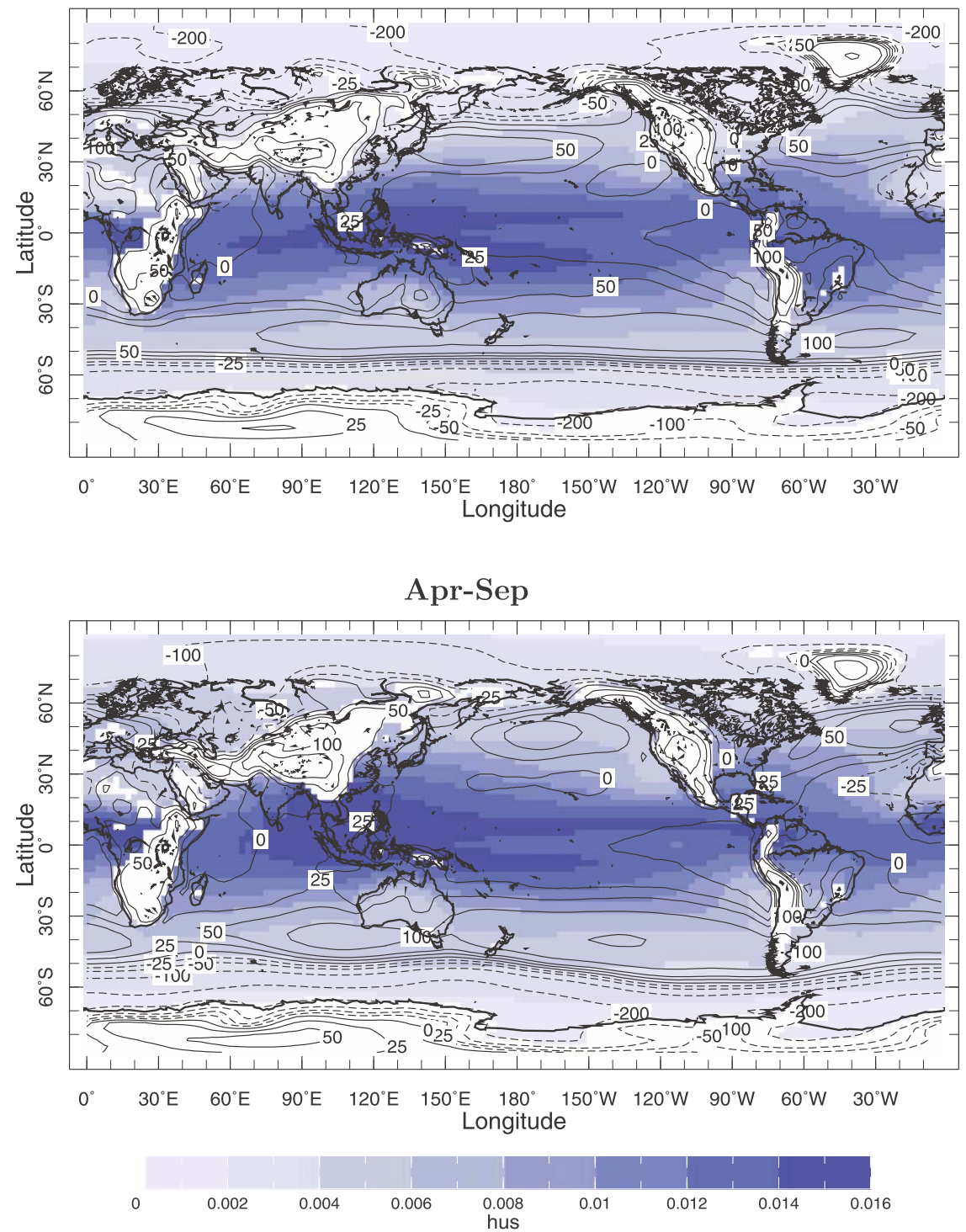

FIG. 9. The twenty-first-century change in the surface pressure $(\mathrm{mb})$ and the twentiethcentury mean specific humidity field $\left(\mathrm{g} \mathrm{kg}^{-1}\right)$ for the (top) October-March and (bottom) AprilSeptember half years.

$$
\begin{aligned}
& \delta \mathrm{TH}_{\mathrm{CC}}=-\alpha \delta T \int_{0}^{p_{s}} \nabla \cdot\left(\overline{\mathbf{u}}_{20} \bar{q}_{20}\right) d p \quad \text { and } \\
& \delta \mathrm{TE}_{\mathrm{CC}}=-\alpha \delta T \int_{0}^{p_{s}} \nabla \cdot\left(\overline{\mathbf{u}^{\prime} q^{\prime}}\right)_{20} d p,
\end{aligned}
$$

where $\alpha=d \ln \left(e_{s}\right) / d T$ and $\delta T$ refers to the latitudinally varying zonal and annual mean temperature change between the surface and $700 \mathrm{mb}$. Hence, the twentieth-century thermodynamic and transient eddy moisture flux convergences are increased as temperature increases with a Clausius-Clapeyron scaling [see
Held and Soden (2006) for more discussion and details]. Calculations were performed for each model before forming the multimodel mean. In Fig. 13 we show the actual change in $P-E$, the ClausiusClapeyron estimated change, $\alpha \delta T(P-E)$, and the changes in the thermodynamic and transient eddy contributions together with their Clausius-Clapeyron estimates.

First of all, as already shown in Held and Soden (2006) but for changes over different periods, the change in $P-$ $E$ is well approximated by a simple Clausius-Clapeyron approximation, except that it overestimates subtropical 


\section{$\delta T H$}
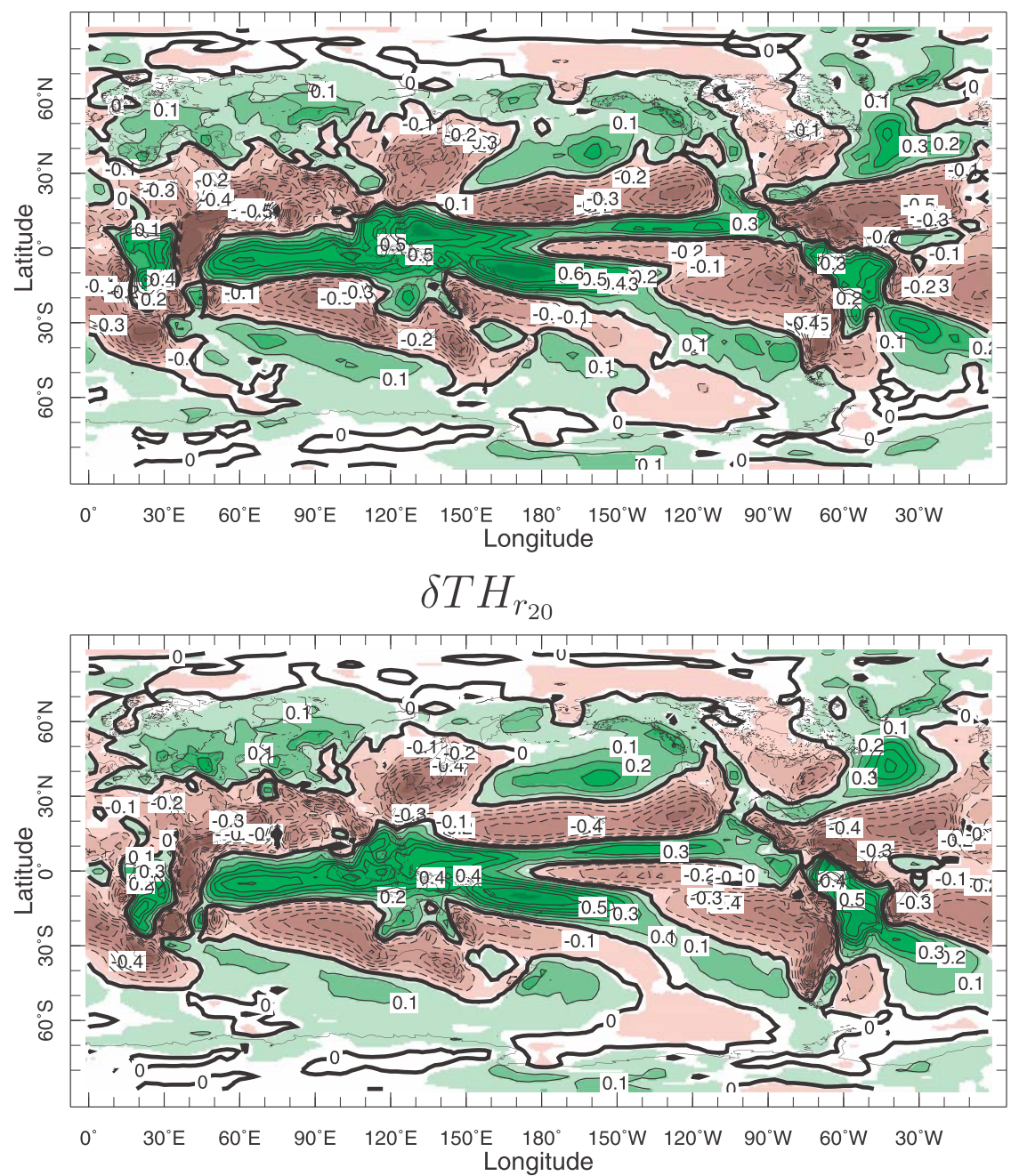

$\delta T H_{\delta r}$

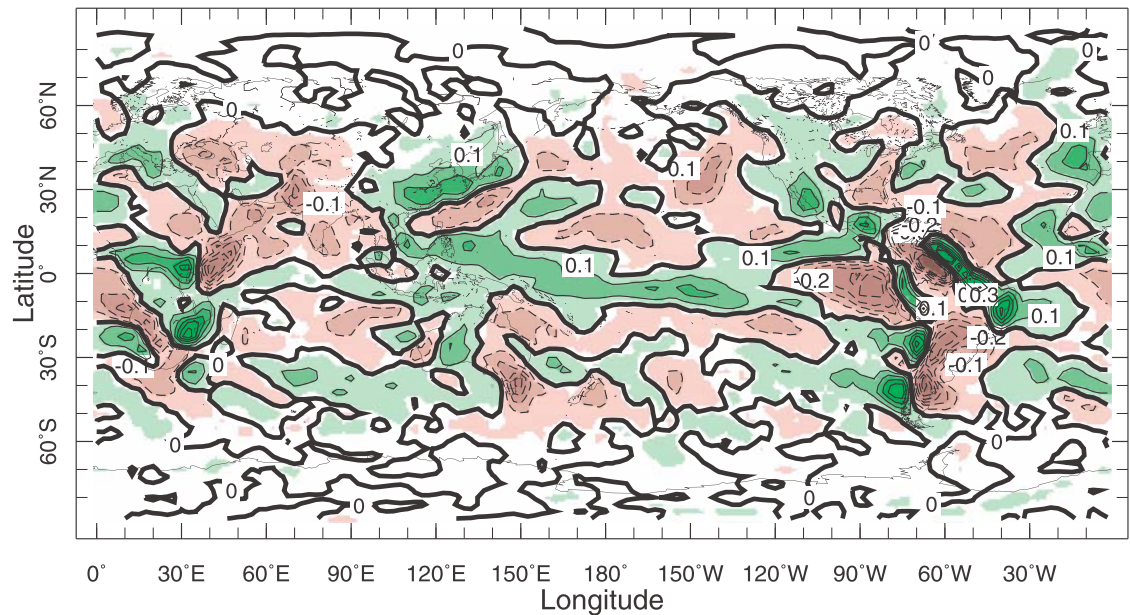

FIG. 10. (top) The twenty-first-century $\delta(P-E)$ tendency for the October-March half year due to $\delta \mathrm{TH}$, (middle) $\delta \mathrm{TH}_{r_{20}}$, and (bottom) $\delta \mathrm{TH}_{\delta_{r}}$. Units are millimeters per day. 


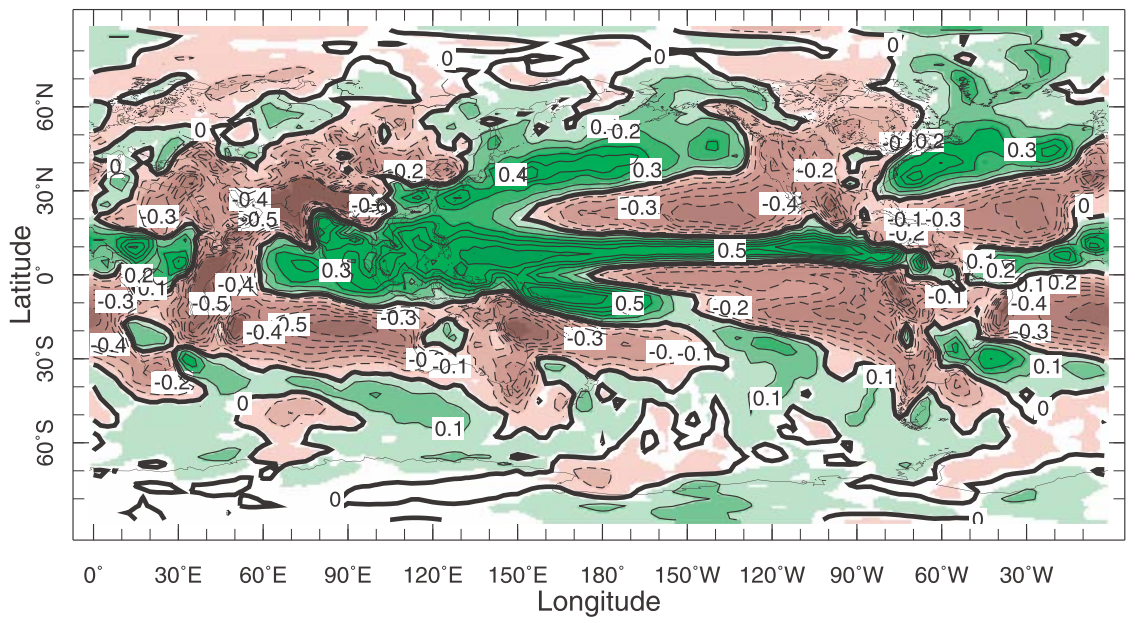

$\delta T H_{r_{20}}$

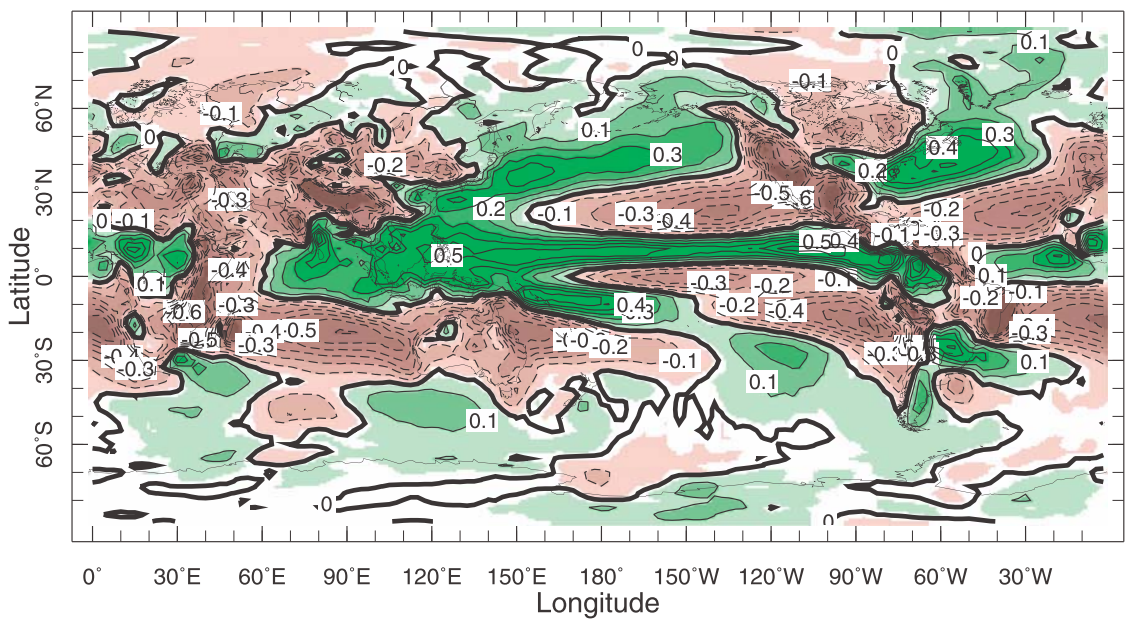

$\delta T H_{\delta r}$

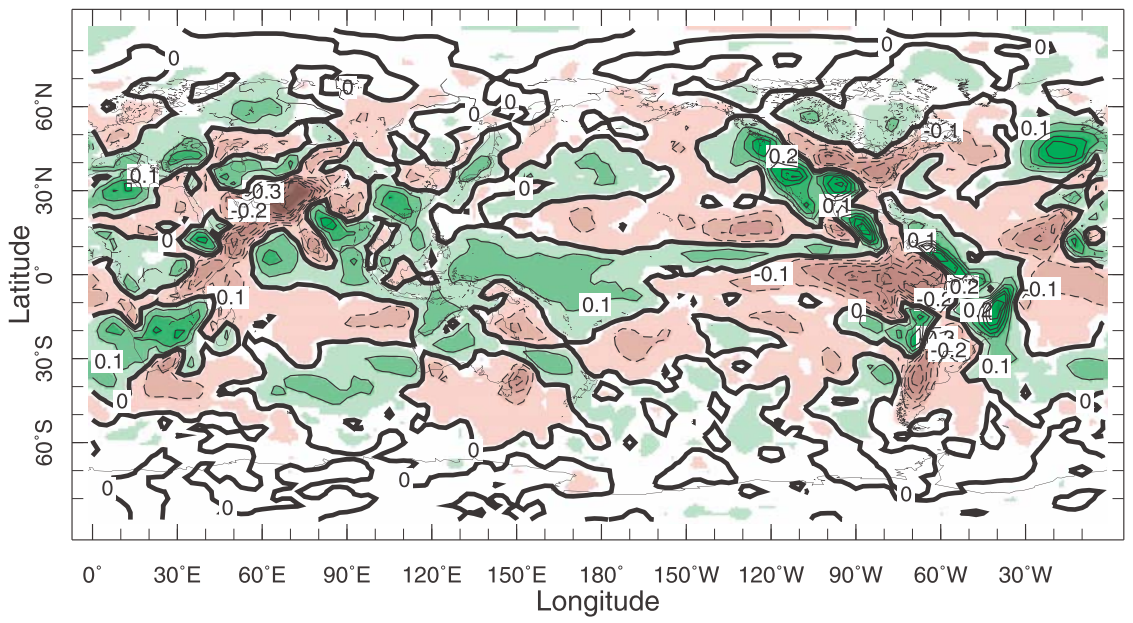

FIG. 11. As in Fig. 10, but for the April-September half year. 

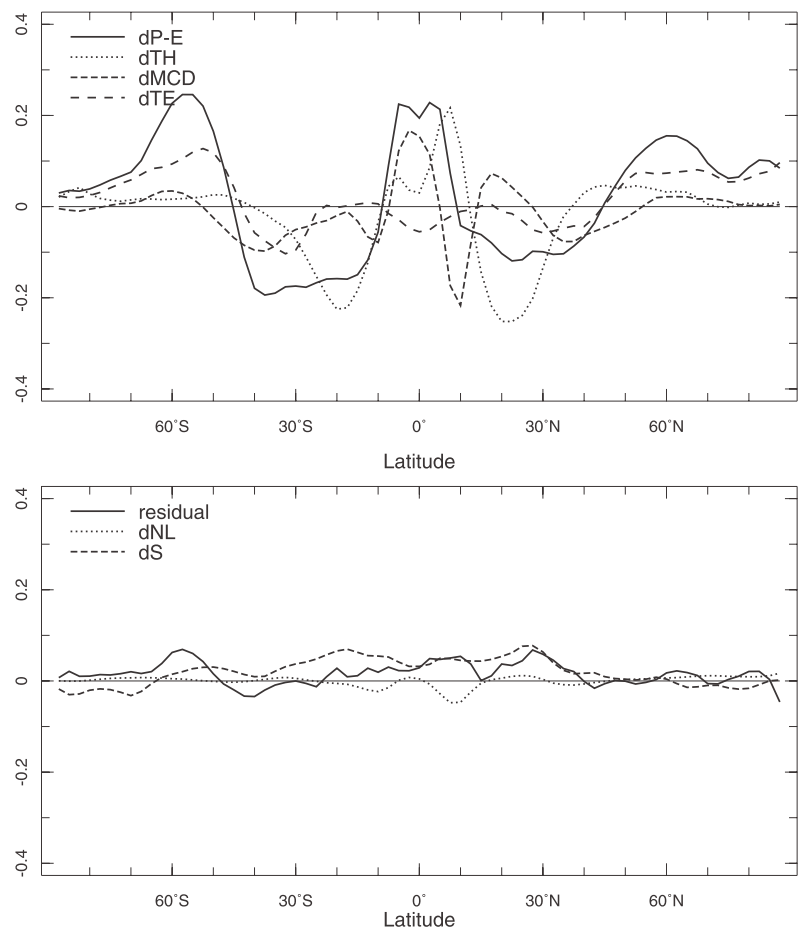

FIG. 12. (top) The annual and zonal mean $\delta(P-E)$ and contributions from $\delta \mathrm{TH}, \delta \mathrm{MCD}$, and $\delta \mathrm{TE}$. (bottom) $\delta \mathrm{NL}$ and $\delta S$ as well as the residual between $\delta(P-E)$ and the sum of the five contributing terms. Units are millimeters per day.

drying, does not capture the poleward extent of the region of subtropical drying, and places the latitude of midlatitude wetting too far equatorward. These differences are accounted for by the dynamic contributions to $P-E$ (the weakening tropical divergent circulation and the poleward shift of meridional circulation cells and storm tracks) as already shown. The change in the thermodynamic contribution estimated from the Clausius-Clapeyron relation also agrees with the actual changes apart from an overestimate of subtropical drying. The change in transient eddy moisture flux convergence is also reasonably approximated by the Clausius-Clapeyron relation. One important exception is that the latitude dividing increased transient eddy convergence from increased divergence is too far equatorward in the Clausius-Clapeyron estimate compared to the actual modeled change. This indicates the poleward shift of the storm tracks that the Clausius-Clapeyron estimate ignores. Some of the remaining differences between the actual and estimated eddy fluxes could arise from changes in the intensity, scale, and character of eddies, as suggested by $\mathrm{Wu}$ et al. (2010). Clearly, while the ClausiusClapeyron relation explains much of the changes in moisture convergences, changes in mean and transient
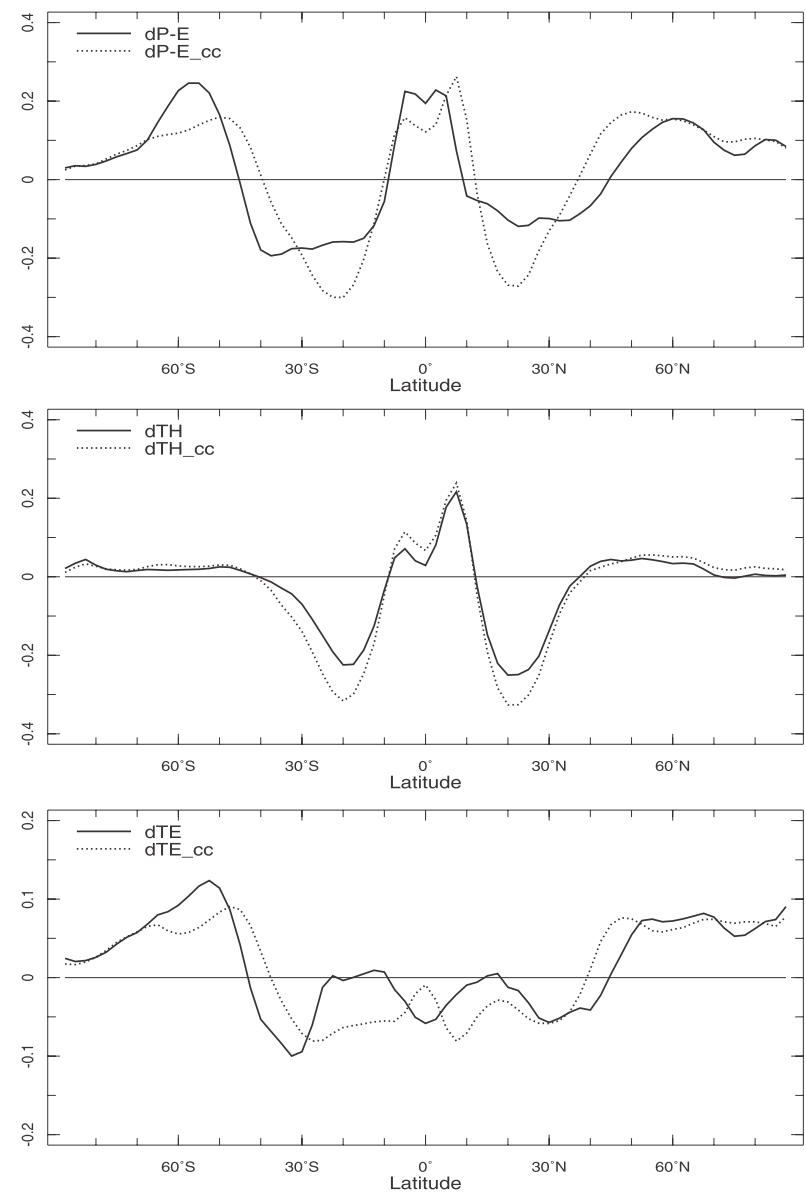

FIG. 13. (top) The annual and zonal mean $\delta(P-E)$ and (middle) contributions from $\delta \mathrm{TH}$ and (bottom) $\delta \mathrm{TE}$ (all with solid lines), together with the changes in these terms estimated by the ClausiusClapeyron relation and the lower-troposphere temperature change (dashed lines). Units are millimeters per day.

circulation must be accounted for to fully explain the modeled changes.

\section{Conclusions}

The causes of changes in the atmospheric hydrological cycle under global warming have been examined using 15 models that were utilized in CMIP3/IPCC AR4 and had all the data required for an analysis of the moisture budget. The main conclusions are as follows:

1) The term $P-E$ changes in the now familiar way with wet areas getting wetter (the ITCZ and mid- to high latitudes) and dry areas getting drier and with a poleward expansion of the subtropical dry zones.

2) Recalculating the change in moisture budget holding the atmospheric circulation fixed shows that a large part of this change in $P-E$ is accounted for by the rise 
in specific humidity that accompanies atmospheric warming.

3) This simple "thermodynamic" component of changes in $P-E$ cannot fully account for the actual changes in $P-E$. In the tropics circulation changes (the "dynamic" contribution) offset to some extent the changes in $P-E$ induced by rising specific humidity because of the slowdown of the tropical divergent circulation. Elsewhere, changes in mean circulation cause drying on the poleward flanks of the Hadley cell because of the poleward shift of the meridional circulation cells related to a Hadley cell expansion and a poleward shift of the storm tracks.

4) Transient eddies strengthen their drying of the subtropics and wetting of the higher latitudes in response to global warming, much of which can also be explained by simple thermodynamics according to the Clausius-Clapeyron relation.

5) A large portion of the thermodynamic contribution to changes in $P-E$ arises from the divergence term, while the advection of changed moisture by the unchanged circulation intensifies over its twentiethcentury pattern as humidity gradients strengthen.

6) A large part of the thermodynamic contribution to changes in $P-E$ comes quite simply from specific humidity increasing according to the ClausiusClapeyron relation with atmospheric warming with fixed relative humidity.

This work provides a relatively complete understanding of the physical mechanisms that underlie projected changes in $P-E$. Confidence in those projections is raised because of the simplicity of the mechanisms involved, especially the thermodynamic ones. As long as specific humidity will increase as the atmosphere warms, a large part of the wet regions getting wetter and dry regions getting drier will occur in response to rising greenhouse gases. This is essentially a certainty. However, changes in the mean circulation also contribute significantly to changes in $P-E$-critically on the poleward margins of subtropical dry zones. While these subtropical changes are known to be related to a projected Hadley cell expansion ( $\mathrm{Lu}$ et al. 2007) and a poleward shift of the storm tracks (Yin 2005), the exact dynamical mechanisms for this remain unclear (Chen et al. 2008; Frierson et al. 2007; Lu et al. 2008; Chou et al. 2009). One argument is that the Hadley cell extent is determined by the latitude at which the mean flow within it becomes baroclinically unstable, and rising static stability in the tropics and subtropics causes this latitude to move poleward (Lu et al. 2007; Frierson et al. 2007); others have suggested that increases in the above-surface meridional temperature gradient and tropopause height are also partly responsible (Wu et al. 2010; Lorenz and DeWeaver 2007b), and Chen et al. (2008) appeal to the effect of changing eddy momentum fluxes caused by increases in transient eddy phase speeds. Much work remains to be done to unravel the relative importance of these, and probably other, processes in determining the causes of the changes in circulation in response to global warming that have a notable effect on the hydrological cycle. The increase in transient eddy moisture fluxes has a robust thermodynamic component that can be simply connected to increasing atmospheric temperatures and moisture (e.g., Held and Soden 2006; Lorenz and DeWeaver 2007a); yet it, too, may also have a partially dynamical explanation (Wu et al. 2010). Explaining all of these phenomena should be a priority to increase our understanding of model projections of hydrological cycle change.

Acknowledgments. This work was supported by NOAA Grants NA03OAR4320179 and NA08OAR4320912, and NSF Grant ATM-08-04107. We thank Isaac Held for his comments on an earlier draft of this paper and three anonymous reviewers for their comments.

\section{APPENDIX}

\section{Imbalances in the Moisture Budget Calculation}

The calculated moisture budget contains a remaining imbalance between $P-E$ and the computed moisture divergence. Figure A1 shows the annual mean residual in the change in the moisture balance after accounting for all the terms in the moisture budget, including the nonlinear term neglected in progressing from Eqs. (1) to (3) and the surface boundary gradient term in Eq. (1). Errors are largest in regions of topography. Errors are first introduced in that the data used have been interpolated from the original model vertical grids onto just nine standard pressure levels. Further, we do not use the same numerical methods for discretization as was used in the models. Also, we use daily data and not data at the time step of the models. In addition, diffusion of moisture within the models is not saved, which could cause errors in regions of large moisture gradients along model levels, as is the case with terrain-following coordinates in mountainous regions. It is notable, for example, that one region of large imbalance is over the Himalayas and Andes. Given the limitation of the model datasets, we do not think that errors could be reduced further. It is notable that the spatial distribution of errors is such as to not compromise the large-scale patterns of hydrological cycle 


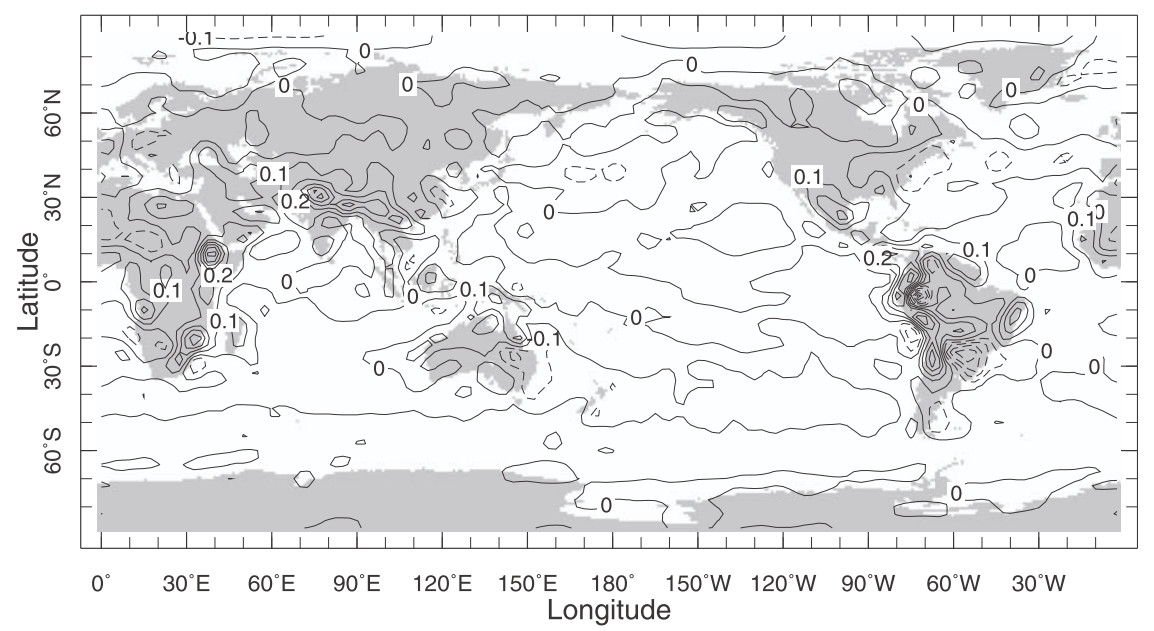

FIG. A1. The annual mean residual imbalance between $\delta(P-E)$ and the change in vertically integrated moisture convergence [including the nonlinear term neglected in Eq. (3)]. Units are millimeters per day.

change focused on here (but would clearly make examining mechanisms of hydrological change in, for example, the Himalayas an error-prone task.)

\section{REFERENCES}

Bengtsson, L., K. I. Hodges, and E. Roeckner, 2006: Storm tracks and climate change. J. Climate, 19, 3518-3543.

Chang, E. K. M., S. Lee, and K. L. Swanson, 2002: Storm track dynamics. J. Climate, 15, 2163-2183.

Chen, G., J. Lu, and D. Frierson, 2008: Phase speed spectra and the latitude of surface westerlies: Interannual variability and global warming trend. J. Climate, 21, 5942-5959.

Chou, C., J. D. Neelin, C.-A. Chen, and J.-Y. Tu, 2009: Evaluating the "rich-get-richer" mechanism in tropical precipitation change under global warming. J. Climate, 22, 1982-2005.

Emori, S., and S. J. Brown, 2005: Dynamic and thermodynamic changes in mean and extreme precipitation under changed climate. Geophys. Res. Lett., 32, L17706, doi:10.1029/2005GL023272.

Frierson, D. M. W., J. Lu, and G. Chen, 2007: Width of the Hadley cell in simple and comprehensive general circulation models. Geophys. Res. Lett., 34, L18804, doi:10.1029/2007GL031115.

Held, I. M., and B. J. Soden, 2006: Robust responses of the hydrological cycle to global warming. J. Climate, 19, 5686-5699.

Holton, J. R., 1992: An Introduction to Dynamic Meteorology. Academic Press, 511 pp.

Liu, Z., S. Vavrus, F. He, N. Wen, and Y. Zhong, 2005: Rethinking tropical ocean response to global warming: The enhanced equatorial warming. J. Climate, 18, 4684-4700.

Lorenz, D. J., and E. T. DeWeaver, 2007a: The response of the extratropical hydrological cycle to global warming. J. Climate, 20, 3470-3484.

$\longrightarrow$, and - 2007b: Tropopause height and the zonal wind response to global warming in the IPCC scenario integrations. J. Geophys. Res., 112, D10119, doi:10.1029/2006JD008087.

Lu, J., G. Vecchi, and T. Reichler, 2007: Expansion of the Hadley cell under global warming. Geophys. Res. Lett., 34, L06805, doi:10.1029/2006GL028443.
— G. Chen, and D. M. W. Frierson, 2008: Response of the zonal mean atmospheric circulation to $\mathrm{El}$ Niño versus global warming. J. Climate, 21, 5835-5851.

Meehl, G., C. Covey, T. Delworth, M. Latif, B. McAvaney, J. F. B. Mitchell, R. J. Stouffer, and K. E. Taylor, 2007a: The WCRP CMIP3 multimodel dataset: A new era in climate change research. Bull. Amer. Meteor. Soc., 88, 1383-1394.

_ Change 2007: The Physical Science Basis, S. Solomon et al., Eds., Cambridge University Press, 747-846.

Previdi, M., and B. G. Liepert, 2007: Annular modes and Hadley cell expansion under global warming. Geophys. Res. Lett., 34, L22701, doi:10.1029/2007GL031243.

Seager, R., and G. A. Vecchi, 2010: Greenhouse warming and the 21st Century hydroclimate of southwestern North America. Proc. Natl. Acad. Sci. USA, in press.

—, R. Murtugudde, N. Naik, A. Clement, N. Gordon, and J. Miller, 2003: Air-sea interaction and the seasonal cycle of the subtropical anticyclones. J. Climate, 16, 1948-1966.

— , and Coauthors, 2007: Model projections of an imminent transition to a more arid climate in southwestern North America. Science, 316, 1181-1184.

Trenberth, K., and C. J. Guillemot, 1995: Evaluation of the global atmospheric moisture budget as seen from analyses. J. Climate, 8, 2255-2272.

Vecchi, G. A., and B. J. Soden, 2007: Global warming and the weakening of the tropical circulation. J. Climate, 20, 43164340.

Wu, Y., M. Ting, R. Seager, H.-P. Huang, and M. A. Cane, 2010: Changes in storm tracks and energy transports in a warmer climate simulated by the GFDL CM2.1 model. Climate Dyn., doi:10.1007/s00382-010-0776-4, in press.

Xie, S.-P., C. Deser, G. A. Vecchi, J. Ma, H. Teng, and A. T. Wittenberg, 2010: Global warming pattern formation: Sea surface temperature and rainfall. J. Climate, 23, 966986.

Yin, J. H., 2005: A consistent poleward shift of the storm tracks in simulations of 21st century climate. Geophys. Res. Lett., 32, L18701, doi:10.1029/2005GL023684. 